\title{
Characteristics of deformity surgery in patients with severe and rigid cervical kyphosis (CK): results of the CSRS-Europe multi-centre study project
}

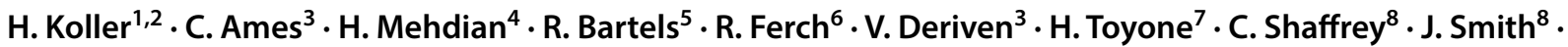 \\ W. Hitzl ${ }^{9} \cdot$ J. Schröder ${ }^{10} \cdot$ Yohan Robinson ${ }^{11}$
}

Received: 2 June 2018 / Revised: 25 October 2018 / Accepted: 15 November 2018 / Published online: 27 November 2018

(c) The Author(s) 2018

\begin{abstract}
Introduction and purpose Little information exists on surgical characteristics, complications and outcomes with corrective surgery for rigid cervical kyphosis (CK). To collate the experience of international experts, the CSRS-Europe initiated an international multi-centre retrospective study.

Methods Included were patients at all ages with rigid CK. Surgical and patient specific characteristics, complications and outcomes were studied. Radiographic assessment included global and regional sagittal parameters. Cervical sagittal balance was stratified according to the CSRS-Europe classification of sagittal cervical balance (types $A-D$ ).

Results Eighty-eight patients with average age of 58 years were included. CK etiology was ankylosing spondlitis $(n=34)$, iatrogenic $(n=25)$, degenerative $(n=9)$, syndromatic $(n=6)$, neuromuscular $(n=4)$, traumatic $(n=5)$, and RA $(n=5)$. Blood loss averaged $957 \mathrm{ml}$ and the osteotomy grade 4.CK-correction and blood loss increased with osteotomy grade $(r=0.4 / 0.6$, $p<.01)$. Patients with different preop sagittal balance types had different approaches, preop deformity parameters and postop alignment changes (e.g. C7-slope, C2-7 SVA, translation). Correction of the regional kyphosis angle (RKA) was average $34^{\circ}(p<.01)$. CK-correction was increased in patients with osteoporosis and osteoporotic vertebrae (POV, $\left.p=.006\right) .22 \%$ of patients experienced a major long-term complication and $14 \%$ needed revision surgery. Patients with complications had larger preop RKA $(p=.01)$, RKA-change $(p=.005)$, and postop increase in distal junctional kyphosis angle $(p=.02)$. The POV-Group more often experienced postop complications $(p<.0001)$ and revision surgery $(p=.02)$. Patients with revision surgery had a larger RKA-change $(p=.003)$ and postop translation $(p=.04) .21 \%$ of patients had a postop segmental motor deficit and the risk was elevated in the POV-Group $(p=.001)$.

Conclusions Preop patient specific, radiographic and surgical variables had a significant bearing on alignment changes, outcomes and complication occurrence in the treatment of rigid CK.
\end{abstract}

Electronic supplementary material The online version of this article (https://doi.org/10.1007/s00586-018-5835-2) contains supplementary material, which is available to authorized users.

Extended author information available on the last page of the article 


\section{Graphical abstract}
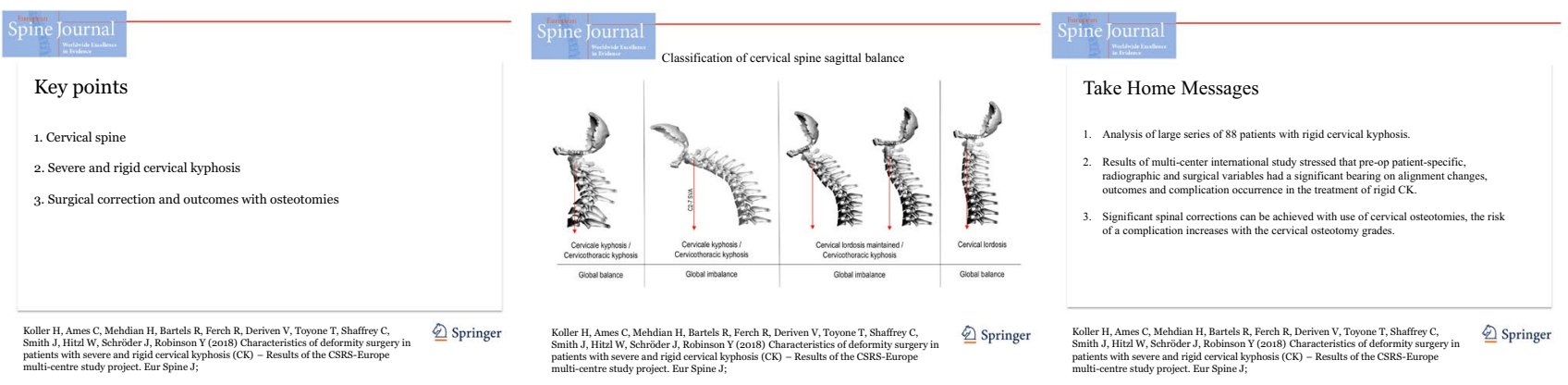

Keywords Cervical spine $\cdot$ Kyphosis $\cdot$ Rigid deformity $\cdot$ Cervical osteotomy

\section{Introduction}

The goals of surgery for rigid cervical kyphosis (CK) are to prevent the natural course of a progressive deformity, restore horizontal visual axis, improve disability, lower pain derived from muscle fatigue, lower the risk of adjacentlevel decompensation, address and treat neurological compromise, and improve respiratory function in severe cases. There is increasing evidence that CK can have significant impact on clinical outcomes after cervical spine surgery. Corrective surgery can improve disability, pain, neurologic function, and health-related quality of life measures in CK patients [1-7]. Several authors have contributed to a better understanding of the occurrence and treatment of $\mathrm{CK}$, as well as the related global spinal alignment changes that $\mathrm{CK}$ can cause [1-4, 8-20].

Kyphotic alignment of the cervical spine per se is not always a pathologic pattern in a healthy patient $[6,21,22]$. However, mechanical and degenerative consequences from CK can cause lasting disability and neck pain due to compensatory efforts to maintain global balance $[14,15]$. Once a CK becomes structural and rigid, treatment and correction become more challenging and the associated risks for complications with surgery increase. Little information exists on the technique-related outcomes and complications associated with treatment of rigid CK. The different alignment patterns of $\mathrm{CK}$ and their implications for surgical correction have not been well defined. These data are of paramount importance to improve the surgical management of CK as well as prevention and treatment of complications.

The current challenges with CK-correction are largely related to the standardization of safe surgical procedures and the understanding of realignment planning, intraoperative corrective manoeuvers, and complication avoidance [20]. Accordingly, to improve our understanding of surgical correction in rigid CK, members of the Cervical Spine Research
Society (CSRS) were invited to participate with their expert experience in an international multi-centre analysis. The objectives were to improve the understanding of related regional and global alignment changes with surgical correction of rigid $\mathrm{CK}$, to identify predictors for both radiographic and clinical outcomes using different surgical strategies, to identify risk factors for complications and revisions surgery, and to characterize differences among various sagittal cervical balance types.

The information derived from analysis of rigid CK may also be useful for the treatment of moderate and semi-rigid $\mathrm{CK}$, since the challenges with treatment of rigid CK resemble a linear technical progression, though stressed, of those characteristics also experienced in the treatment of moderate and semi-rigid CK. Findings in the current study may be helpful in patient consultation and planning of cervical deformity surgery.

\section{Patients and methods}

This was a retrospective multi-centre study on the results of corrective surgery for rigid CK. Following invitation of the European CSRS (CSRS-E), surgeons of 9 spine centres agreed to participate in this retrospective study.

The primary inclusion criteron was a CK treated surgically using modern anterior screw-plate and/or posterior screw-rod constructs. The definition of rigid CK was based on either CT imaging that demonstrated intervertebral fusion or synostoses or flexion-extension radiographs that showed no motion at the CK apex (defined as $\leq 2^{\circ}$ motion). In comparison to rigid CK, semi-rigid CK partly corrects on active flexion-extension films, in supine position, with manual traction or in halo-traction films, but it does not achieve lordotic alignment. Flexible CK completely or nearly completely corrects by active or passive motion. 
The included treatment period was between 2003 and 2014, and participating surgeons were required to submit consecutive cases from their respective practices. Each participating site received detailed instruction sheets for radiographic measurement and assessment of outcome variables. Minimum follow-up for clinical outcomes was 6 months, however, patients were included with less follow-up for the purpose of analysing surgical correction and perioperative complications.

\section{Radiographic variables}

Analysis of full-standing bi-planar radiographs was the preferred method at preop, postop, and follow-up if available. Measurements were derived from standing radiographs (cervical and/or full-standing).

Radiographic assessment included global and regional sagittal parameters (Fig. 1): C7-Slope (C7S), C2-C7 angle, $\mathrm{C} 2-\mathrm{C} 7$ angle on extension films or halo-traction films,
$\mathrm{C} 0-\mathrm{C} 2$ angle, regional kyphosis angle (RKA), and distal junctional kyphosis angle (DJK-angle [23]). The authors defined the sagittal vertical axis of $\mathrm{C} 2, \mathrm{C} 7$ and $\mathrm{S} 1$ and measured their respective differences (C2-C7 SVA, C7-S1 SVA, and C2-S1 SVA). Sagittal vertebral translation (SVT) of the upper relative to the adjacent-level lower vertebra at the osteotomy level was measured in $\mathrm{mm}$ and expressed as a percentage (Fig. 2). The differences of radiographic measurements at the distinct time points were calculated.

Cervical sagittal balance was stratified based on regional and global balance according to the CSRS-E classification system [20] (types $A$ to $D$ ). This classification scheme was designed in 2009 and has proven to be a useful and efficient approach for the assessment of CK based on regional and global balance in the hands of CSRS-E surgeons. Regional cervical balance was analysed using the SVA concept. It is an easy to apply classification of cervical balance and alignment and reflects the global balance of a patient with CK (Fig. 3).
Fig. 1 Illustration of radiographic measurements

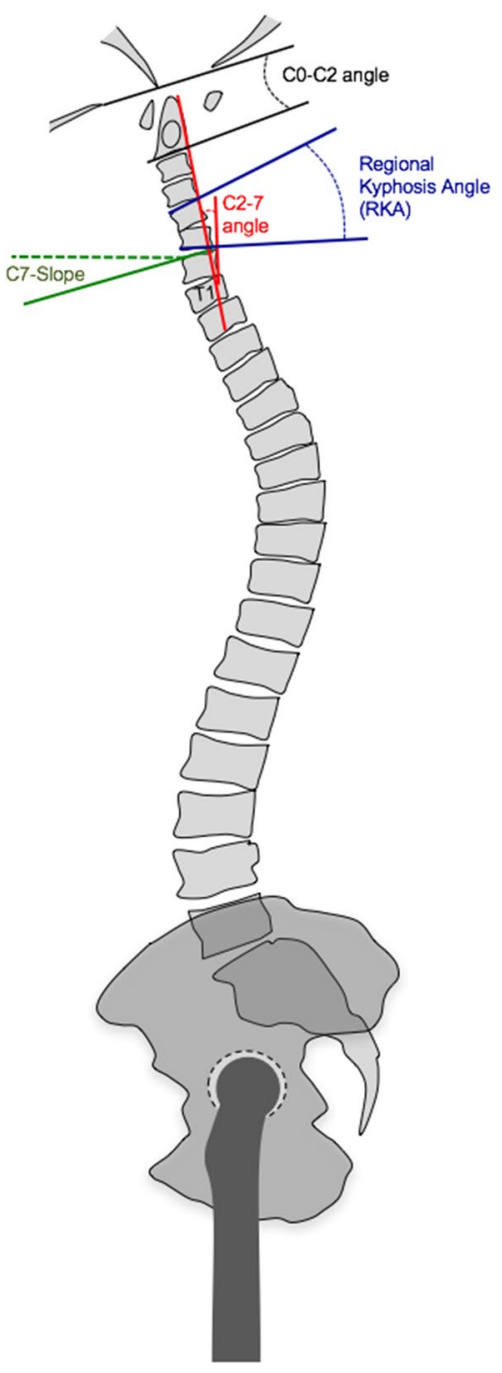




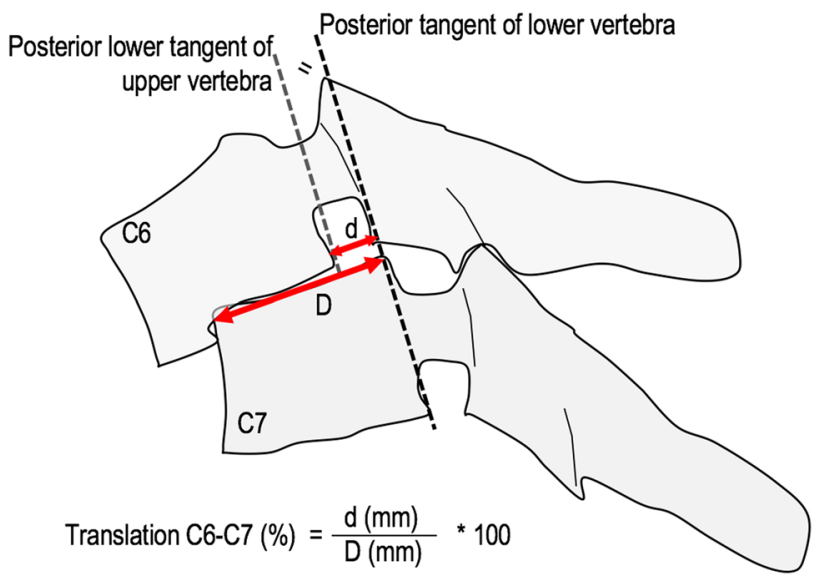

Fig. 2 Illustration of measurement of segmental sagittal vertebral translation (SVT) $(\%)$

The CK shape was descriptively stratified into angular versus arc-shape and numerically defined by the deformity angular ratio (DAR). The DAR resembles the ratio of CK and the number of vertebrae in the kyphosis $\left(\mathrm{DAR}=\mathrm{CK}\left({ }^{\circ}\right) /\right.$ number of vertebra $(n))$.

The degree of C2-7 angle change on halo-traction film versus extension films was calculated in patients that had both imaging modalities available.

Radiographic fusion was assessed on post-operative radiographs and/or CT imaging. The imaging modality utilized was noted (radiographs vs. CT).

\section{Clinical variables}

Multiple clinical and surgical variables were studied, including sex, patient age, body mass index (BMI), and etiology of kyphosis. Patients with evidence of osteoporosis or osteoporotic vertebrae (POV) as in rheumatism or syndromic disease were defined as POV-Group for statistical analysis. Also, previous surgeries, tobacco use, as well as the presence of cervical spondylotic myelopathy (CSM) were noted. Grading of medical comorbidities was done using the American Society of Anesthesiology (ASA)-scoring system (1-6). Spinal cord function was studied using the ASIA-scoring system (A to E).

Clinical outcome measures included the Neck Disability Index (NDI) and the visual analogue scale (VAS)-scoring of the Euroquol-5D-5L (EQ-VAS) survey. Where available, preop and postop values were compared. The recorded overall satisfaction with surgery was classified as very satisfied/ satisfied or indifferent/not satisfied.

\section{Surgical variables}

Patient files were reviewed for blood loss, surgical time, use of intra-operative neuromonitoring (IONM), and surgical techniques including implant types.

The osteotomy applied was classified according to the classification of osteotomies and soft-tissue reported by Ames [23] (Fig. 4). In addition, 3-column osteotomies were classified into open-wedge osteotomies (OWO, e.g. SPO),

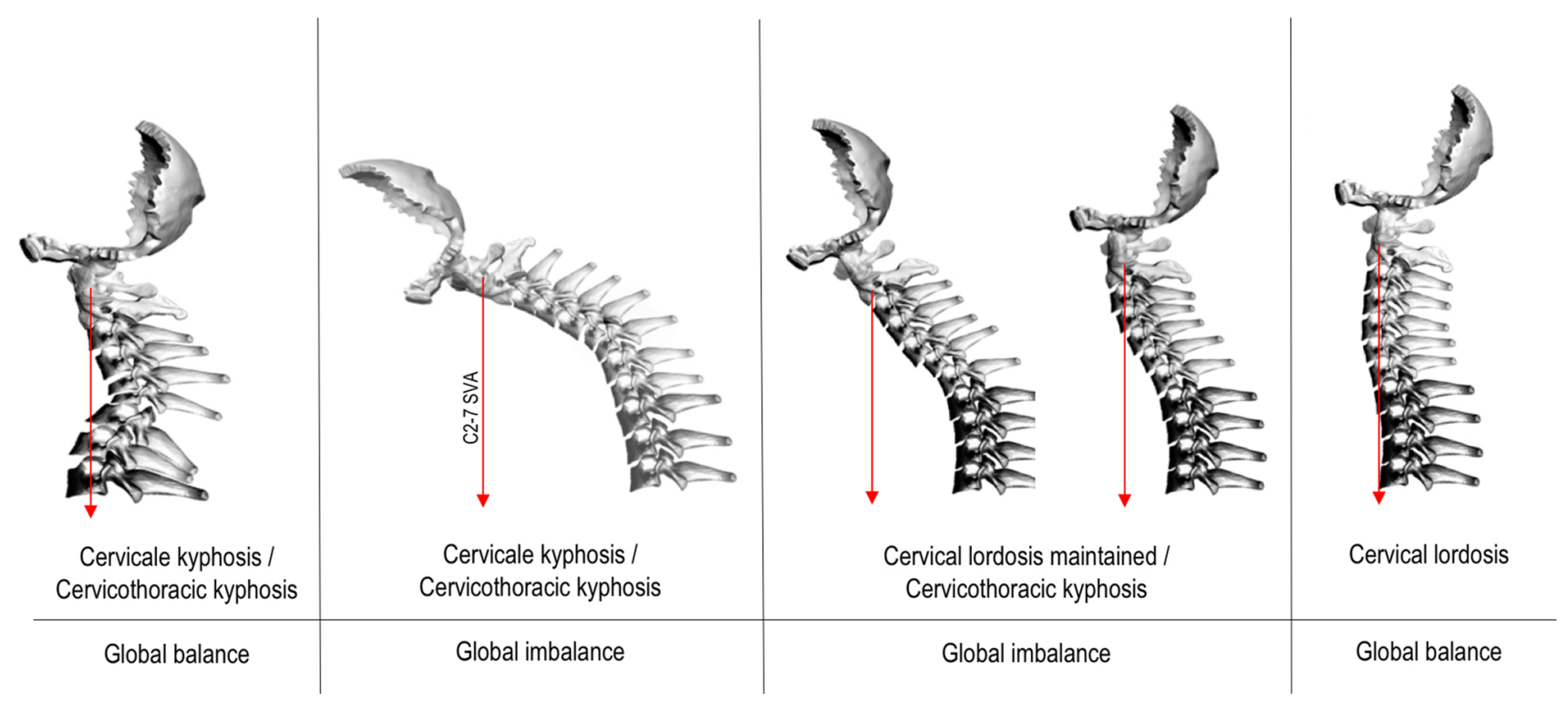

Fig. 3 Classification of cervical sagittal balance according to the shape of the cervical and cervicothoracic spine, the cervical balance measured (C2-C7 SVA) and measures of global balance (C7-S1 SVA, not shown). For cervical regional balance, measures suggest- ing a physiologic range in healthy individuals include a C2-C7 SVA of about 20-30 $\pm 10 \mathrm{~mm}[10,22]$. For trunk imbalance, measures of imbalance include a C7-S1 SVA and C7-plumb line falling anterior to the hip axis 


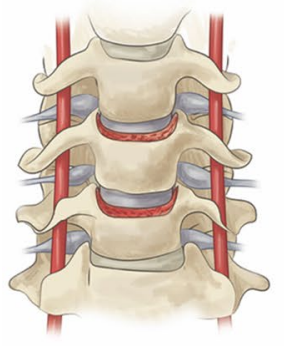

Grade 1

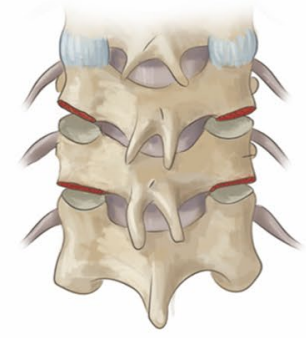

Grade 1

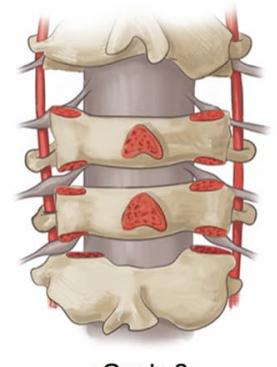

Grade 2

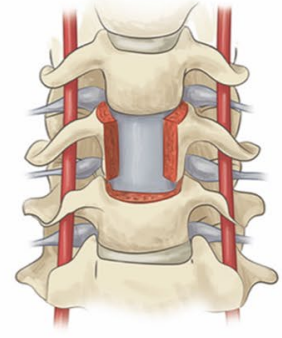

Grade 3

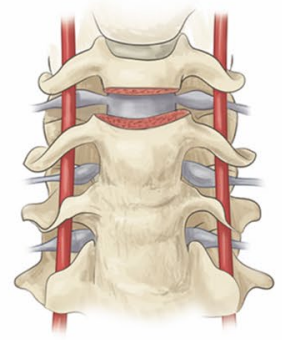

Grade 4

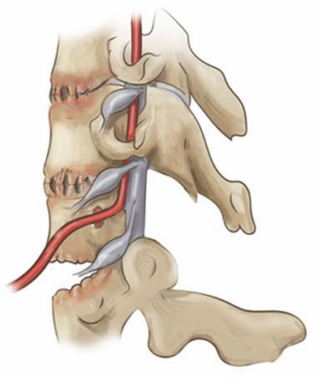

Grade 5

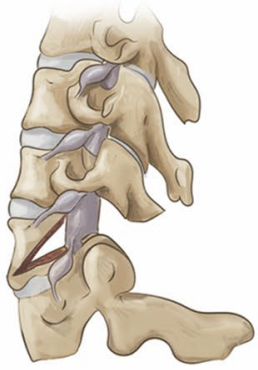

Grade 6

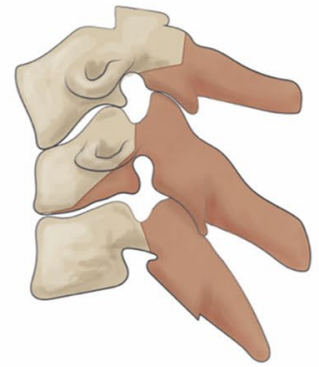

Grade 6

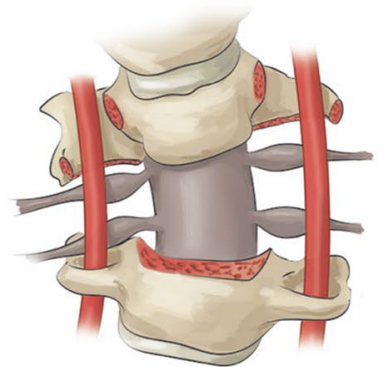

Grade 7
Fig. 4 Modified classification of cervical osteotomies according to the original work of Ames et al. Grades 1-7. Grades 5 to 7 resemble 3-column osteotomies (3CO) such as SPO (Grade 5), PSO and $Y$-type osteotomy (Grade 6), and vertebral column resection (Grade

closing-wedge osteotomies (CWO, e.g. PSO), and closingopening wedge osteotomies (COWO, e.g. $Y$-type osteotomy [20]) including also asymmetric osteotomy variants [20, 24]. The highest degree of cervical osteotomy applied in each patient was recorded in those patients with different osteotomy techniques at multiple levels. Perioperative major and minor complications were graded according to Glassmann [25]. Any wound-related complications as well as distal junctional failure indicating a revision surgery were recorded.

The occurrence of any postop central or segmental motor deficit was recorded and stratified according to MRC-grades (Medical research council grading system, 1-5). Bilateral and unilateral lesions were noted and the worst MRC-grade was recorded, and the referred nerve root and spinal cord level defined. A lasting postop muscle motor function of MRC $\leq 3$ was graded as a major complication.

Intraoperative and immediate post-operative complications were differentiated as well as any complication that occurred during longer-term follow-up ( $>3$ months postop, after hospital discharge). Any postop observed distal junctional kyphosis (DJK) was noted in the surgeons detailed complication reporting.

The need for revision surgery (performed, scheduled or offered to the patient) was noted and defined as any surgery necessary as a consequence of the index surgery.
7). Grades 6 require more predural dissection as compared to a Grade 5 explaining differences in grading the complexity of the osteotomy. Grade 5 and Grade 6 osteotomies include also asymmetric SPO [20] and PSO [24]

Patient files were analysed in detail whether patients had anterior, posterior or combined surgery, whether they had staged or non-staged same-day surgeries as well as for the use of preop and/or perioperative traction therapy. The fusion levels were recorded, and the end-levels were recorded as upper-most and lower-most instrumented vertebrae (UIV and LIV). The application of corpectomy and the use of autograft versus allograft and bone substitutes were recorded.

The postop days of ventilation were calculated, and the longest duration was selected for statistical analysis in patients with staged surgeries.

\section{Statistical methods}

Data consistency was checked and screened for outliers as well as normality by using quartile plots. Continuous variables were also tested for normality using the Kolmogrov-Smirnov test. Cross tabulation tables were computed and analysed using Fisher's Exact test or Pearson's Chisquared test. Independent and dependent Student $t$ tests were used to test continuously distributed variables when assumptions were fulfilled. Pearson's and Spearman correlation coefficients were computed and tested. One factorial ANOVA as well as repeated ANOVA models were applied and corresponding LSD tests for pairwise comparisons of 
means. 95\% confidence intervals for means were computed and illustrated using whisker plots. All reported tests were two-sided. $p$ values $<.05$ were considered as statistically significant. If distinct data for variables studied in subgroup analyses were not complete at all time points, the numbers of available data points for statistical comparisons are reported ('valids $=n$ '). All statistical analyses were performed by use of STATISTICA 13 (StatSoft, Tulsa, OK/USA).

\section{Results}

Eighty-eight patients that had surgical correction of rigid CK fulfilled the inclusion criteria and were included in the present study. The number of submitted cases varied by participating site (e.g. $n=36, n=14, n=13, n=10, \ldots$ ).

\section{Surgical and clinical results}

The mean age of patients at surgery was 58 years. Clinical baseline variables are summarized in Table 1 and surgical group characteristics are summarized in Table 2.

Blood loss averaged $957 \mathrm{ml}$ and osteotomy grade averaged 4.2. RKA-correction and blood loss significantly increased with osteotomy grade $(r=0.4 / r=0.6, p<.01)$ as did the correction of other deformity variables $(\mathrm{C} 7 \mathrm{~S}, \mathrm{C} 2-7$ angle, C2-7 SVA; $r=.27$ to $r=.5, p=.01$ to $p<.01$ ) and SVT $(r=.28, p=.03)$. Blood loss also correlated with surgical time $(r=.4, p<.01)$, ASA-score $(r=.3, p=.009)$, and RKA-correction $(r=.26, p<.021)$.

With increased magnitude of preop deformity $(\mathrm{C} 7 \mathrm{~S}$, C2-7 angle, C2-7 SVA, and RKA), the utilized osteotomy grade increased $(r=0.33$ to $r=0.61, p<.001)$. The surgeons selected osteotomy grades $\geq 5$ in patients with smaller DAR (4.9 vs. 9.5, $p=.001$ ). With increasing DAR the RKAcorrection $(r=.37, p<.0001)$ and SVT $(r=.56, p<.001)$ increased.

Multiple differences existed among sagittal cervical balance types. The mean osteotomy grade significantly increased from Type $A$ (3.6) to Type $B$ (4.1) and to Type $C$ (5.5) with significant differences among Types $A$ and $C$ as well as Types $B$ and $C(p<.01)$. Distribution of CSM prevalence was significantly different $(p=.03)$ among Type $A(66 \%)$, Type $B(36 \%)$ and Type $C(12 \%)$. Likewise, the incidence of POV varied (Type $A 22 \%$, Type $B 44 \%$, Type $C 65 \%, p=.01$ ) as did the number of patients with LIV $\leq \mathrm{T} 2$ (Type $A 60 \%$, Type $B 30 \%$, and Type $C 0 \%, p<.001$ ).

Analysis of NDI change in 33 patients with preop and follow-up NDI data showed a significant decrease from preop $47.5 \pm 22.3$ to postop $29.1 \pm 22.5(p<.01)$. The follow-up results for EQ-VAS score are recorded in Table 2. At followup, NDI improvement was $18.5(p<.01)$. Patients with larger residual $\mathrm{C} 2-7$ angle had worse NDI scores at follow-up
Table 1 Baseline group characteristics of 88 patients with rigid cervical kyphosis

\begin{tabular}{ll}
\hline Variable & Mean \pm 1 SD (range) \\
\hline Patient age preoperative (years) & $56 \pm 16(6-84)$ \\
Follow-up (months) & $26.4 \pm 20.6(0-90)^{*}$ \\
Body mass index & $28 \pm 16(15-51)$ \\
Deformity angular ratio & $7.3 \pm 7.2(1-36)$ \\
ASA-score & $2.7 \pm 0.8(1-4)$ \\
Male/female patients & $29 / 59$ \\
Diagnosis/etiology & \\
Ankylosing spondylitis & $n=34(38.6 \%)$ \\
Iatrogenic/post-surgery & $n=25(28.4 \%)$ \\
Degenerative & $n=9(10.2 \%)$ \\
Syndrome-related & $n=6(6.8 \%)$ \\
Post-traumatic & $n=5(5.7 \%)$ \\
Rheumatoid arthritis & $n=5(5.7 \%)$ \\
Neuromuscular disease & $n=4(4.5 \%)$ \\
Tobacco use/smokers & $n=15(19 \%)$ of 77 pts** \\
Osteoporosis & $n=35(39.8 \%)$ \\
POV-group & $n=53(60.2 \%)$ \\
Non-POV-group & $n=37(42 \%)$ \\
Evidence of CM & $n=51(58 \%)$ \\
Yes & \\
No &
\end{tabular}

Pts patients, $C M$ cervical myelopathy, $P O V$ patients with osteoporosis or osteoporotic vertebrae as per definition, ASA American Society of Anesthesiologists

*Including patients with postop mortality; **If information fon specific variables was not available in all patients the valid numbers are reported

$(r=.45, p=.002)$. Better deformity correction showed better postop NDI and follow-up C2-7 angle $(r=.31, p=.029$; $n=48)$ and C2-C7 SVA $(r=-.36, p=.01 ; n=48)$. Accordingly, a larger NDI improvement was seen with better correction of the $\mathrm{C} 2-7$ angle $(r=.46, p=008)$ and $\mathrm{C} 2-\mathrm{C} 7$ SVA $(r=.48, p=.005 ; n=33) .89 \%$ of patients were very satisfied/satisfied with the outcome. These patients had better postop correction of the C2-C7 SVA $(25 \pm 27 \mathrm{~mm}$ vs. $-3.5 \pm 46 \mathrm{~mm}, p=.03)$ and C2-S1 SVA $(24 \pm 40 \mathrm{~mm}$ vs. $-33 \pm 51 \mathrm{~mm}, p=.01$ ), and they had less postop change of the DJK-angle $\left(-4^{\circ} \pm 9^{\circ}\right.$ vs. $\left.7^{\circ} \pm 9^{\circ}, p=.01\right)$. Patients with complications or revision surgery had worse NDI (see complications section).

The surgical approach had no significant influence on RKA-correction. The distribution of UIV and LIV is summarized in Fig. 5. Fifty-seven patients $(65 \%)$ had fusion caudal to T2 $(>\mathrm{T} 2)$. The POV-Group was more likely to have fusion extending caudal to T2 $(86 \%$ vs. $51 \%, p=.02)$. Patients with LIV $>$ T2 were treated with higher osteotomy grades $(4.7 \pm 1.7$ vs. $3.1 \pm 1.6, p<.001)$, had greater blood loss $(1160 \pm 696 \mathrm{ml}$ vs. $541 \pm 394 \mathrm{ml}, p<.001, n=77)$, and 
Table 2 Surgical variables and results in 88 patients with correction of rigid cervical kyphosis

\begin{tabular}{|c|c|c|}
\hline Variable & Mean \pm 1 SD (range) & Valids** \\
\hline Highest osteotomy grade & $4.2 \pm 1.8(1-6)$ & \\
\hline Opening wedge osteotomy (OWO) & $n=26(29.5 \%)$ & \\
\hline Closing-wedge osteotomy (CWO) & $n=20(22.7 \%)$ & \\
\hline Closing-Opening-Wedge osteotomy (COWO) & $n=3(3.4 \%)$ & \\
\hline CWO or COWO & $n=23(26.1 \%)$ & \\
\hline Spinal level of CWO or COWO $(n)$ & C6-7 (1), C7 (15), C7-T1 (2), T1 (5) & \\
\hline Estimated blood loss (ml) & $956.8 \pm 677.2(50-3600)$ & $n=82 \mathrm{pts}$ \\
\hline Number of vertebrae in CK $(n)$ & $5 \pm 2.9(1-16)$ & \\
\hline Surgery time & $380.6 \pm 131.6 \mathrm{~min} .(118-658 \mathrm{~min})$. & $n=79 \mathrm{pts}$ \\
\hline Levels fused & $7.6 \pm 2.6(1-22)$ & \\
\hline Duration of ventilation (days) $* * *$ & $0.4 \pm 1(0-7)$ & $n=73 \mathrm{pts}$ \\
\hline \multicolumn{3}{|l|}{ Approach strategy } \\
\hline Anterior-only & $n=7(8 \%)$ & \\
\hline Posterior-only & $n=48(54.5 \%)$ & \\
\hline Antero-posterior & $n=18(20.5 \%)$ & \\
\hline Antero-postero-anterior & $n=3(3.5 \%)$ & \\
\hline Postero-anterior & $n=2(2.3 \%)$ & \\
\hline Postero-antero-posterior & $n=8(9.1 \%)$ & \\
\hline Postero-antero-postero-anterior & $n=2(2.3 \%)$ & \\
\hline Combined approaches & $n=35(39.8 \%)$ & \\
\hline Staged surgery & $n=8(9.1 \%)$ & \\
\hline Interval between surgeries & $6.4 \pm 5.3$ days ( $1-14$ days $)$ & \\
\hline $\mathrm{LIV}>\mathrm{T} 2$ & $n=66(75 \%)$ & \\
\hline \multicolumn{3}{|l|}{ Cervical traction } \\
\hline Any kind of preoperative traction & $n=10(11.4 \%)$ & \\
\hline Anterior surgical release with subsequent post-operative traction & $n=3(3.5 \%)$ & \\
\hline Posterior surgical release with traction including intraoperative traction & $n=14(15.9 \%)$ & \\
\hline Post-operative traction & $n=1(1.1 \%)$ & \\
\hline Preoperative halo-gravity traction & $n=8(9.1 \%)$ & \\
\hline Traction time (days), excluding intraop traction & $3 \pm 2.2(1-7)$ & \\
\hline Anterior cervical corpectomy & $n=16(18.2 \%)$ & \\
\hline \multicolumn{3}{|l|}{ Bone graft material $^{\mathrm{a}}$} \\
\hline Autograft & $n=46(52 \%)$ & \\
\hline Allograft & $n=23(26 \%)$ & \\
\hline Bone graft substitutes & $n=19(21 \%)$ & \\
\hline Intraoperative neuromonitoring & $n=59(67 \%)$ & $n=85 \mathrm{pts}$ \\
\hline Bony fusion & $n=74(87 \%)$ & $n=85 \mathrm{pts}$ \\
\hline Information on osseus fusion by CT-scans ${ }^{\mathrm{b}}$ & $n=51(61 \%)$ & $n=83 \mathrm{pts}$ \\
\hline \multicolumn{3}{|l|}{ Clinical results } \\
\hline EQ-VAS at follow-up & $71.7 \pm 17.1(10-92)$ & $n=32 \mathrm{pts}$ \\
\hline NDI preop & $46.9 \pm 21.5(0-80)$ & $n=37 \mathrm{pts}$ \\
\hline NDI Postop & $27.0 \pm 22.9(0-80)$ & $n=48 \mathrm{pts}$ \\
\hline NDI change & $18.5 \pm 22.6(60$ to -24$)$ & $n=33 \mathrm{pts}$ \\
\hline
\end{tabular}

LIV lowest instrumented vertebra

*Acc. to modified Ames-classification, see Fig. 4; **Number of complete data points for specific variables are listed if other than 100\%; ***Ventilation until 1st post-operative day indicates 1 day of ventilation

${ }^{\text {a } M a i n ~ g r a f t ~ m a t e r i a l ~ n o t e d ~}$

${ }^{\mathrm{b}}$ All pts with follow-up had fusion assessment on radiographs 

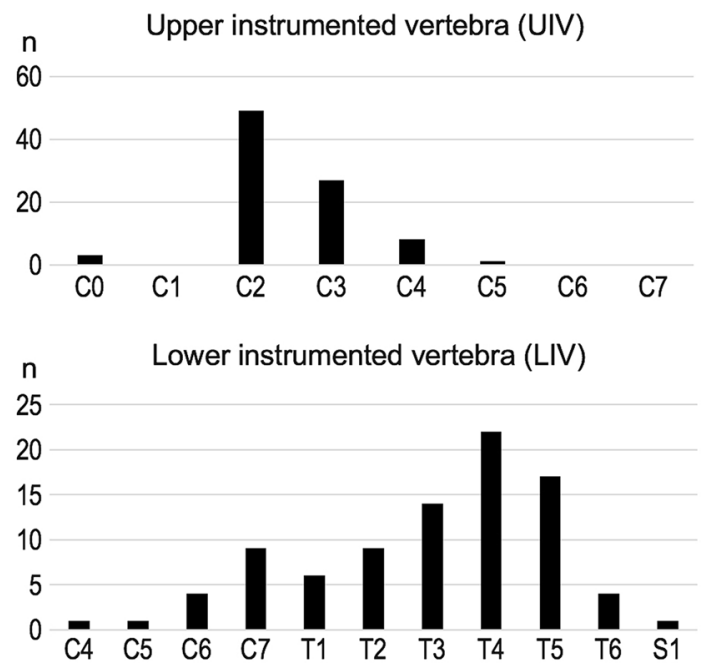

Fig. 5 Distribution of upper and lower instrumented vertebrae (UIV/ LIV) among 88 patients

had a greater preop $\mathrm{C} 7 \mathrm{~S}\left(54.7^{\circ} \pm 26.3^{\circ}\right.$ vs. $18.3^{\circ} \pm 19.7^{\circ}$, $p<.001$ ).

\section{Radiographic results}

Definition of rigid CK with intervertebral fusion on CT imaging was documented in $97 \%$ of patients and two patients fulfilled inclusion criteria based on flexion-extension films. Pre-operatively 64 patients (73\%) had an arc-shaped CK and 24 patients $(27 \%)$ had an angular shape.

Classification of sagittal cervical balance was as follows: $36 \%$ Type $A(n=32), 44 \%$ Type $B(n=39)$, and $19 \%$ Type $C(n=17)$. The surgical approach strategy was significantly different according to this classification $(p<.001)$. Posterior-only surgery was significantly favored for Type $C(94 \%)$ compared to Type $B(56 \%)$ and Type $A(28 \%)$ deformities $(p<.001)$. Patients with different sagittal cervical balance types had significantly different preop deformity parameters and postop alignment changes. These striking differences are summarized in Table 3 and illustrated in Fig. 7.

Preop RKA was $26.9^{\circ} \pm 21^{\circ}$ and postop RKA was $-7.8^{\circ} \pm 20.8^{\circ}$ in 88 patients with rigid CK. The correction was $34.4^{\circ} \pm 15.8^{\circ}(p<.0001)$ with a narrow $95 \%$ confidence interval of $31^{\circ}-37^{\circ}$. Radiographic results and comparisons are summarized in Table 4.

Postop correction of C2-C7 SVA significantly correlated with the highest osteotomy grade $(r=.04, p<.001, n=80)$ as well as the postop C2-7 angle ( $r=-0.3, p=.01, n=83$ ). In return, the $\mathrm{C} 2-\mathrm{C} 7 \mathrm{SVA}$ showed significant correlation with the RKA-correction postop $(r=.022, p=.047, n=80$ ) and at follow-up $(r=.28, p=.01, n=78)$. Perioperative traction did not influence RKA-correction in comparison to patients without traction. Traction was likely used to help improve surgical safety in selected patients.

Postop SVT-change averaged $13 \%$ (-25\% to 63\%, $n=61)$ and was significantly correlated with RKA-correction $(r=0.4, p=.004)$ and preop RKA $(r=.51, p<.001)$, as was the correction of C2-C7 SVA $(r=.02, p=.047)$ and C2-S1 SVA $(r=.34, p=.02)$. Preop to postop mean SVT was significantly greater in patients with correction of angular versus arc-shaped CK (20\% vs. $5 \%, p=.002)$, while the osteotomy grade had no influence on postop SVT. Likewise, SVT showed an inverse correlation with the number of vertebrae included in the kyphotic curve $(r=-.29, p=0.25)$.

Analysis of radiographic measures over time showed a significant postop improvement of the C2-7 SVA $(p<.0001)$, the C2-S1 SVA $(p<.02$ to $p<.0001)$ with a mild increase of the C7-S1 SVA $(p=.02)$. The postop change of the $\mathrm{C} 2-\mathrm{C} 7 \mathrm{SVA}(r=.02, p=.047)$ and the change of the C2-S1 SVA $(r=.34, p=.02)$ correlated significantly with the RKA-correction. Significant compensatory postop changes were also noted in the $\mathrm{C} 0-\mathrm{C} 2$ angle $(p<.0003)$, the $\mathrm{C} 2-\mathrm{C} 7$ angle $(p<.00001)$ and the $\mathrm{C} 7 \mathrm{~S}(p=.03)$. For the $\mathrm{C} 7 \mathrm{~S}$, a strong correlation was seen with the $\mathrm{C} 2-\mathrm{C} 7$ SVA preop as well as postop $(r=.69, p<.001, n=78)$. The physiologic interdependences between the spinal regions are illustrated in Fig. 6. The distinct postop changes of cervical alignment and varying alignment behaviours among the different types of sagittal cervical balance are illustrated in Fig. 7.

The change of the C2-7 angle on neutral lateral films compared to the $\mathrm{C} 2-7$ angle on traction films (halo-traction, calliper traction, manual traction) or active extension films was $-5.5^{\circ} \pm 12.1^{\circ}$ (valids $=47$ ) stressing an overall rigid cervical spine. Notably, in the POV-Group this difference was $-13.8^{\circ} \pm 13.7^{\circ}$ compared to $-3^{\circ} \pm 10.5^{\circ}(p=.008)$ in the Non-POV-Group. Also, in the POV-Group RKA-correction was significantly increased $\left(41^{\circ} \pm 13^{\circ}\right.$ vs. $30^{\circ} \pm 16^{\circ}$, $p<.001)$ as was the change of the C2-C7 SVA $(27 \pm 28 \mathrm{~mm}$ vs. $11 \pm 25 \mathrm{~mm}, p=.01$ ), while changes in the DJK-angle were not significantly different.

The difference between the $\mathrm{C} 2-7$ angle on traction films and extension films in 8 patients with both radiographs available for analysis averaged $4.5^{\circ}$ in favour of the extension film.

\section{Complications}

The distribution of complications and incidences is summarized in Table 5.

Stratification of postop segmental motor deficits according to osteotomy types (OWO vs. CWO/COWO) showed that $31 \%$ (8 of 26 patients) with OWO had MRC $\leq 4$ and $30 \%$ ( 7 of 23 patients) with CWO/COWO had MRC $\leq 4.15 \%$ (4 of 26 patients) with OWO had MRC $\leq 3$ and $17 \%$ (4 of 23 
Table 3 Distribution of radiographic results among different sagittal cervical balance types (type $A-C$ )

\begin{tabular}{|c|c|c|c|c|c|c|}
\hline Radiographic variable & Type $A$ & Type $B$ & Type $C$ & $\begin{array}{l}\text { Difference } A \\
\text { versus } B\end{array}$ & Difference $A$ versus $C$ & $\begin{array}{l}\text { Difference } \\
B \text { versus } C\end{array}$ \\
\hline Patient age (years) & $50 \pm 19.1$ & $60.9 \pm 13.1$ & $56.4 \pm 12.8$ & $p=.008$ & ns & ns \\
\hline Number of vertebrae in CK $(n)$ & $4.4 \pm 2.7$ & $5.5 \pm 3$ & $5 \pm 3$ & ns & $\mathrm{ns}$ & $\mathrm{ns}$ \\
\hline Number of pts with LIV > T2 & $59 \%$ & $31 \%$ & $0 \%$ & $p<.001$ & $p<.001$ & $p<.001$ \\
\hline Combined approach & $59.4 \%$ & $33 \%$ & $5.9 \%$ & ns & $p<.001$ & $p=.005$ \\
\hline Posterior-only approach & $28.1 \%$ & $56.4 \%$ & $94.1 \%$ & $p<.0001$ & $p<.0001$ & $p<.0001$ \\
\hline Preop C7S $\left(^{\circ}\right)$ & $22.5 \pm 24.3$ & $50.1 \pm 28.2$ & $63.3 \pm 18.8$ & $p<.001$ & $p=<.001$ & $p=.048$ \\
\hline Postop C7S $\left({ }^{\circ}\right)$ & $28.8 \pm 18.1$ & $40.2 \pm 19.7$ & $44.9 \pm 11.9$ & $p=.02$ & $p<.001$ & ns \\
\hline Follow-up C7S $\left(^{\circ}\right)$ & $27.1 \pm 15.5$ & $39.1 \pm 18.5$ & $43.1 \pm 11.6$ & $p=.007$ & $p<.001$ & $\mathrm{~ns}$ \\
\hline Change C7S preop versus postop $\left({ }^{\circ}\right)$ & $-6.5 \pm 17$ & $10.5 \pm 22.2$ & $18.4 \pm 16.1$ & $p<.01$ & $p<.01$ & ns \\
\hline Change C7S preop versus FU $\left(^{\circ}\right)$ & $-4.6 \pm 18$ & $7.9 \pm 23.8$ & $20.2 \pm 18.3$ & $p=.02$ & $p<.01$ & $p=.05$ \\
\hline Preop C2-C7 angle $\left(^{\circ}\right)$ & $17.8 \pm 23.7$ & $21.1 \pm 25.8$ & $1 \pm 24.3$ & ns & $p=.02$ & $p<.01$ \\
\hline Postop C2-7 angle $\left({ }^{\circ}\right)$ & $-3.8 \pm 20$ & $-3.3 \pm 26.6$ & $-20.7 \pm 13.2$ & $\mathrm{~ns}$ & $p=.001$ & $p=.002$ \\
\hline Follow-up C2-C7 angle $\left(^{\circ}\right)$ & $-1.3 \pm 18.6$ & $-0.1 \pm 20.9$ & $-11.3 \pm 22.5$ & $\mathrm{~ns}$ & ns & ns \\
\hline Change $\mathrm{C} 2-7$ angle preop versus postop $\left(^{\circ}\right)$ & $21.1 \pm 20.8$ & $25.7 \pm 23.3$ & $21.7 \pm 22.4$ & $\mathrm{~ns}$ & $\mathrm{~ns}$ & ns \\
\hline Change $\mathrm{C} 2-7$ angle preop versus FU $\left(^{\circ}\right)$ & $18.5 \pm 24.7$ & $24.3 \pm 23.7$ & $12.3 \pm 27.9$ & $\mathrm{~ns}$ & $\mathrm{~ns}$ & $\mathrm{~ns}$ \\
\hline Preop $\mathrm{C} 0-\mathrm{C} 2$ angle $\left({ }^{\circ}\right)$ & $34.7 \pm 14.1$ & $35.4 \pm 16.8$ & $36.1 \pm 11.6$ & $\mathrm{~ns}$ & ns & $\mathrm{ns}$ \\
\hline Postop C0-C2 angle $\left(^{\circ}\right)$ & $26.5 \pm 12.4$ & $28.6 \pm 12.9$ & $31.7 \pm 14$ & $\mathrm{~ns}$ & ns & ns \\
\hline Follow-up $\mathrm{C} 0-\mathrm{C} 2$ angle $\left({ }^{\circ}\right)$ & $28.3 \pm 12.7$ & $31.9 \pm 12.6$ & $33.3 \pm 10.7$ & $\mathrm{~ns}$ & ns & $\mathrm{ns}$ \\
\hline Change preop versus postop $\mathrm{C} 0-\mathrm{C} 2$ angle $\left(^{\circ}\right)$ & $21.1 \pm 20.8$ & $25.7 \pm 23.3$ & $21.7 \pm 22.4$ & $\mathrm{~ns}$ & ns & ns \\
\hline Change preop versus $\mathrm{FU} \mathrm{C} 0-\mathrm{C} 2$ angle $\left(^{\circ}\right)$ & $18.5 \pm 24.7$ & $24.3 \pm 23.7$ & $12.3 \pm 27.9$ & $\mathrm{~ns}$ & ns & ns \\
\hline Preop RKA $\left(^{\circ}\right)$ & $31.2 \pm 23.5$ & $27.3 \pm 21.1$ & $17.9 \pm 12.1$ & $\mathrm{~ns}$ & $p=01$ & $p=.04$ \\
\hline Postop RKA $\left({ }^{\circ}\right)$ & $0.1 \pm 18.5$ & $-8.4 \pm 19.4$ & $-20.4 \pm 14.7$ & $\mathrm{~ns}$ & $p<.001$ & $p=.015$ \\
\hline Follow-up RKA $\left(^{\circ}\right)$ & $0 \pm 19.7$ & $-4.9 \pm 20.4$ & $-20 \pm 15$ & $\mathrm{~ns}$ & $p<.001$ & $p=.005$ \\
\hline Change preop versus postop RKA $\left({ }^{\circ}\right)$ & $31.1 \pm 14.2$ & $35.4 \pm 18.1$ & $38.3 \pm 12$ & $\mathrm{~ns}$ & ns & ns \\
\hline Change preop versus FU RKA $\left(^{\circ}\right)$ & $31.2 \pm 14.1$ & $33.8 \pm 19$ & $37.9 \pm 12.2$ & ns & ns & ns \\
\hline Preop C2-7 SVA (mm) & $31 \pm 26.2$ & $67.6 \pm 30.9$ & $83.3 \pm 21.9$ & $p<.01$ & $p<.01$ & $p=.06$ \\
\hline Postop C2-7 SVA (mm) & $32.2 \pm 26$ & $42.8 \pm 23.3$ & $45 \pm 15.8$ & ns & $p=.04$ & ns \\
\hline Follow-up C2-7 SVA (mm) & $31.7 \pm 25.1$ & $47.8 \pm 2.7$ & $43.3 \pm 16.6$ & $p<.01$ & ns & ns \\
\hline Change preop versus postop C2-7 SVA (mm) & $-0.4 \pm 18.1$ & $22.3 \pm 27$ & $38.3 \pm 21.9$ & $p<.01$ & $p<.01$ & $p=.02$ \\
\hline Change preop versus FU C2-7 SVA (mm) & $-1.2 \pm 20.7$ & $18.7 \pm 29.5$ & $40 \pm 22.7$ & $p<.01$ & $p<.01$ & $p<.01$ \\
\hline Preop C2-S1 SVA (mm) & $26.4 \pm 23.9$ & $122.8 \pm 6$ & $133.7 \pm 56.3$ & $p<.01$ & $p<.01$ & $p=.02$ \\
\hline Postop C2-S1 SVA (mm) & $73.9 \pm 37.8$ & $104.6 \pm 61.3$ & $105.2 \pm 54.3$ & ns & ns & ns \\
\hline Follow-up C2-S1 SVA (mm) & $59.7 \pm 62.7$ & $86.2 \pm 64.5$ & $89.4 \pm 43.1$ & $\mathrm{~ns}$ & ns & $\mathrm{ns}$ \\
\hline Change preop versus postop $\mathrm{C} 2-\mathrm{S} 1 \mathrm{SVA}(\mathrm{mm})$ & $-21.7 \pm 43.7$ & $17.8 \pm 47.5$ & $28.4 \pm 42.8$ & $\mathrm{~ns}$ & $p=.03$ & $\mathrm{~ns}$ \\
\hline Change preop versus FU C2-S1 SVA (mm) & $-5 \pm 52.4$ & $-20.9 \pm 49$ & $44.3 \pm 37.6$ & ns & $p=.01$ & $\mathrm{~ns}$ \\
\hline Preop C7-S1 SVA (mm) & $-3.6 \pm 26.9$ & $54.2 \pm 55$ & $54.4 \pm 35.2$ & $p<.001$ & $p<.001$ & $\mathrm{~ns}$ \\
\hline Postop C7-S1 SVA (mm) & $36 \pm 30.6$ & $62.4 \pm 48.9$ & $66.3 \pm 37.8$ & $\mathrm{~ns}$ & $p=.048$ & $\mathrm{~ns}$ \\
\hline Follow-up C7-S1 SVA (mm) & $36.8 \pm 50.3$ & $43.5 \pm 50.3$ & $51 \pm 31.1$ & ns & ns & $\mathrm{ns}$ \\
\hline Change preop versus postop C7-S1 SVA (mm) & $-39 \pm 34.4$ & $-8.7 \pm 33.4$ & $-11.9 \pm 31.6$ & $p=.03$ & ns & $\mathrm{ns}$ \\
\hline Change postop versus FU C7-S1 SVA (mm) & $-25.6 \pm 50.4$ & $-2 \pm 45.3$ & $3.4 \pm 35.2$ & ns & ns & $\mathrm{n}$ \\
\hline Preop DJK $\left(^{\circ}\right)$ & $7.4 \pm 9.9$ & $14.9 \pm 10.8$ & $15 \pm 3.5$ & $p<.01$ & $p<.01$ & ns \\
\hline Postop DJK $\left(^{\circ}\right)$ & $9 \pm 10.9$ & $17 \pm 9$ & $16.2 \pm 5.2$ & $p<.01$ & $p=.03$ & $\mathrm{~ns}$ \\
\hline Follow-up $\left({ }^{\circ}\right)$ & $11.1 \pm 14$ & $16.9 \pm 9.9$ & $19.6 \pm 9.6$ & ns & ns & ns \\
\hline Change preop versus postop DKJ $\left(^{\circ}\right)$ & $-2.2 \pm 10.9$ & $-1.5 \pm 8.5$ & $-1 \pm 6.5$ & ns & ns & $\mathrm{ns}$ \\
\hline Change preop versus FU DJK $\left(^{\circ}\right)$ & $-3.8 \pm 13.1$ & $-2.3 \pm 12.9$ & $-4.5 \pm 9.5$ & ns & ns & ns \\
\hline Preop SVT $(\%)$ & $17.3 \pm 22.1$ & $14.3 \pm 17.8$ & $7.5 \pm 9.9$ & $\mathrm{~ns}$ & ns & ns \\
\hline Postop SVT (\%) & $5 \pm 10.3$ & $0.9 \pm 10$ & $15.5 \pm 11.9$ & $\mathrm{~ns}$ & ns & ns \\
\hline Follow-up SVT (\%) & $0.6 \pm 7.3 \%$ & $1 \pm 9.4$ & $7.8 \pm 10.4$ & $\mathrm{~ns}$ & ns & ns \\
\hline Change preop versus postop SVT (\%) & $13.6 \pm 21.8$ & $12.5 \pm 15.2$ & $-8 \pm 19.8$ & ns & $p=.03$ & $p<.01$ \\
\hline Change preop versus FU SVT (\%) & $17.9 \pm 26.5$ & $10.7 \pm 12.9$ & $-0.3 \pm 18.1$ & ns & ns & ns \\
\hline
\end{tabular}

Illustration of alignment differences among patients with rigid CK type $A, B$ or $C$. Differences for post-operative alignment changes among type $A-C$ are also shown

FU follow-up, LIV lowest instrumented vertebra, SVA sagittal vertical axis, SVT sagittal vertebral translation 
Table 3 (continued)

Table 4 Radiographic results and post-operative changes in 88 patients with surgical correction of rigid CK

\begin{tabular}{|c|c|c|c|c|c|c|c|}
\hline Radiographic variable & Preop & Postop & Follow-up & $\begin{array}{l}\text { Difference preop } \\
\text { versus postop }\end{array}$ & $\begin{array}{l}\text { Difference preop } \\
\text { versus FU }\end{array}$ & $\begin{array}{l}\text { Difference } \\
\text { postop versus FU }\end{array}$ & Valids* \\
\hline $\operatorname{RKA}\left(^{\circ}\right)$ & $27.5 \pm 20.9$ & $-6.4 \pm 19.1$ & $-6.1 \pm 20.3$ & $p<.001$ & $p<.001$ & ns & 83 \\
\hline C7-Slope $\left({ }^{\circ}\right)$ & $40.2 \pm 29.5$ & $35.6 \pm 18.1$ & $34.7 \pm 17.1$ & $p=.03$ & $p=.01$ & $\mathrm{~ns}$ & 78 \\
\hline $\mathrm{C} 2-\mathrm{C} 7$ angle $\left({ }^{\circ}\right)$ & $16.5 \pm 25.5$ & $-5.9 \pm 21.9$ & $-3.7 \pm 20.1$ & $p<.001$ & $p<.001$ & ns & 81 \\
\hline $\mathrm{C} 0-\mathrm{C} 2$ angle $\left({ }^{\circ}\right)$ & $35.7 \pm 14.7$ & $28.5 \pm 12.5$ & $30.9 \pm 12.4$ & $p<.001$ & $p<.001$ & $\mathrm{~ns}$ & 62 \\
\hline C2-7 SVA (mm) & $56.9 \pm 34.9$ & $39.6 \pm 22.6$ & $41.2 \pm 23.6$ & $p<.001$ & $p<.001$ & $\mathrm{~ns}$ & 77 \\
\hline C2-S1 SVA (mm) & $113.1 \pm 67.6$ & $95.3 \pm 52.4$ & $83.6 \pm 64.4$ & $p=.02$ & $p<.001$ & $\mathrm{~ns}$ & 41 \\
\hline C7-S1 SVA (mm) & $41.2 \pm 50.4$ & $55.5 \pm 37.4$ & $47.3 \pm 45.8$ & $p=.02$ & ns & $\mathrm{ns}$ & 43 \\
\hline DJK-angle $\left(^{\circ}\right)$ & $11 \pm 10.5$ & $12.8 \pm 10.6$ & $14 \pm 12.9$ & ns & $p=.04$ & ns & 51 \\
\hline SVT (\%) & $14.6 \pm 18.8$ & $4 \pm 11.3$ & $1.6 \pm 9$ & $p<.001$ & $p<.001$ & ns & 57 \\
\hline
\end{tabular}

$R K A$ regional maximum kyphosis angle, $F U$ follow-up, $S V A$ sagittal vertebral translation

*Number of complete data points for all three time points (preop, postop, follow-up), valids listed if other than $100 \%$ of patients (e.g. because of insufficient radiographic visualization, loss to long-term follow-up or death)

patients) with CWO/COWO had MRC $\leq 3$. The differences were not significant.

Fifty-two percent of patients (46 patients) had highest osteotomy grade $\geq 5$ and the incidence of segmental motor deficits MRC $\leq 4$ was $30.4 \%$. In 41 patients with osteotomy grade $<5$ this incidence was $24 \%$. $20 \%$ of patients ( 9 of 46 patients) with osteotomy grade $\geq 5$ had MRC $\leq 3$ and $24 \%$ (10 of 41 patients) with osteotomy grade $<5$ had MRC $\leq 3$. The differences were not statistically significant. The DAR and the osteotomy type also did not correlate with motor deficits. However, the risk for any segmental motor deficit was elevated in patients of the POV-Group (38\% vs. $9 \%$, $p=.001)$. In the POV-Group, the risk for postop segmental motor deficit $\mathrm{MRC} \leq 3$ was also more likely (32\% vs. $6 \%, p<.001)$. On a continuous scale, a worse postop MRCgrade correlated with age $(r=-0.37, p=.02)$, preop RKA $(r=-.037, p=.04)$, postop deformity correction (change of C7S ( $r=0.44, p=.008), \mathrm{C} 2-7$ angle $(r=-3.6, p=.03)$ and C2-7 SVA $(r=.45, p=006)$ ), and in particular with the severity of SVT $(r=-0.55, p=.005)$. At follow-up, MRCgrade averaged 4.5 (see Table 5), and only two patients had $\mathrm{MRC} \leq 3$.

ASIA-scoring data were available in 70 patients. Except for four patients, all other patients revealed preop and postop ASIA Type $D$ or $E$. One patient with Type $B$ improved to Type $D$, another with Type $C$ improved to Type $D$ and two patients with Type $A$ maintained their respective functional levels. One patient with $3 \mathrm{CO}$ declined from Type $E$ to permanent Type $C$. Three patients had preop and postop but not follow-up ASIA-scoring data available due to death or loss to long-term follow-up.
An immediate postop complication occurred in $43 \%$ and the risk increased with age $(61 \pm 14$ yrs. vs. $52 \pm 17$ yrs., $p=.01)$, BMI ( $29 \pm 7$ vs. $27 \pm 5, p=.048)$, surgery time $(415 \pm 102 \mathrm{~min}$. vs. $350 \pm 147 \mathrm{~min}, p=.03)$, ASA-score (2.9 vs. $2.5, p=006)$, blood loss $(1212 \pm 800 \mathrm{ml}$ vs. $747 \pm 469 \mathrm{ml}$, $p=.001)$ and greater preop deformity $(\mathrm{C} 7 \mathrm{~S} / p=.047, \mathrm{C} 2-7$ $\mathrm{SVA} / p=.048, \mathrm{C} 2-\mathrm{S} 1 \mathrm{SVA} / p=.01, \mathrm{C} 7-\mathrm{S} 1 \mathrm{SVA} / p=.01)$. The risk for an immediate postop complication also increased in the POV-Group (69\% vs. $26 \%, p<.001$ ) and in patients with LIV $>$ T2 (51\% vs. $29 \%, p=0.48)$.

A major long-term complication occurred in $22 \%$ of patients. These patients had significantly longer surgery times $(449 \pm 149 \mathrm{~min}$. vs. $364 \pm 121 \mathrm{~min} ., p=.04)$, greater preop RKA $\left(37^{\circ} \pm 26^{\circ}\right.$ vs. $\left.24^{\circ} \pm 19^{\circ}, p=.01\right)$ and SVT $(28 \pm 25 \%$ vs. $12 \pm 17 \%, p<.01)$, as well as larger RKAcorrection $\left(43^{\circ} \pm 15^{\circ}\right.$ vs. $\left.32^{\circ} \pm 15^{\circ}, p=.006\right)$. They also had worse NDI scores at follow-up $(53 \pm 26 \%$ vs. $23 \pm 20 \%$, $p<.001)$ and worse EQ-VAS $(52.8 \pm 31$ vs. $77 \pm 15$, $p<.001)$. Major complications were more likely in smokers ( $57 \%$ vs. $20 \%$ ), though the difference did not reach statistical significance $(p=.08)$.

Revision surgery was indicated in $26 \%$. These patients had greater RKA-correction $\left(42^{\circ} \pm 15^{\circ}\right.$ vs. $\left.31^{\circ} \pm 15^{\circ}, p=.003\right)$, blood loss $(1237 \pm 837 \mathrm{ml}$ vs. $842 \pm 574 \mathrm{ml}, p=.02)$, larger postop $\mathrm{C} 7 \mathrm{~S}\left(43.4^{\circ} \pm 17^{\circ}\right.$ vs. $\left.34^{\circ} \pm 18^{\circ}, p=.03\right)$, SVT $(10 \pm 13 \%$ vs. $2 \pm 9 \%, p=.01)$, and the DJK-angle $\left(18^{\circ} \pm 6^{\circ}\right.$ vs. $\left.11^{\circ} \pm 10^{\circ}, p=.02\right)$ as well as a larger postop increase of DJK-angle $\left(-8^{\circ} \pm 11^{\circ}\right.$ vs. $\left.0^{\circ} \pm 8^{\circ}, p=.007, n=56\right)$. These patients also had a worse NDI at follow-up $(46 \pm 25 \%$ vs. $20 \pm 18 \%, p<.001)$. The risk for revision was higher in the POV-Group (39\% vs. $17 \%, p<.001)$ and in smokers $(54 \%$ vs. $23 \%, p=.03)$. 

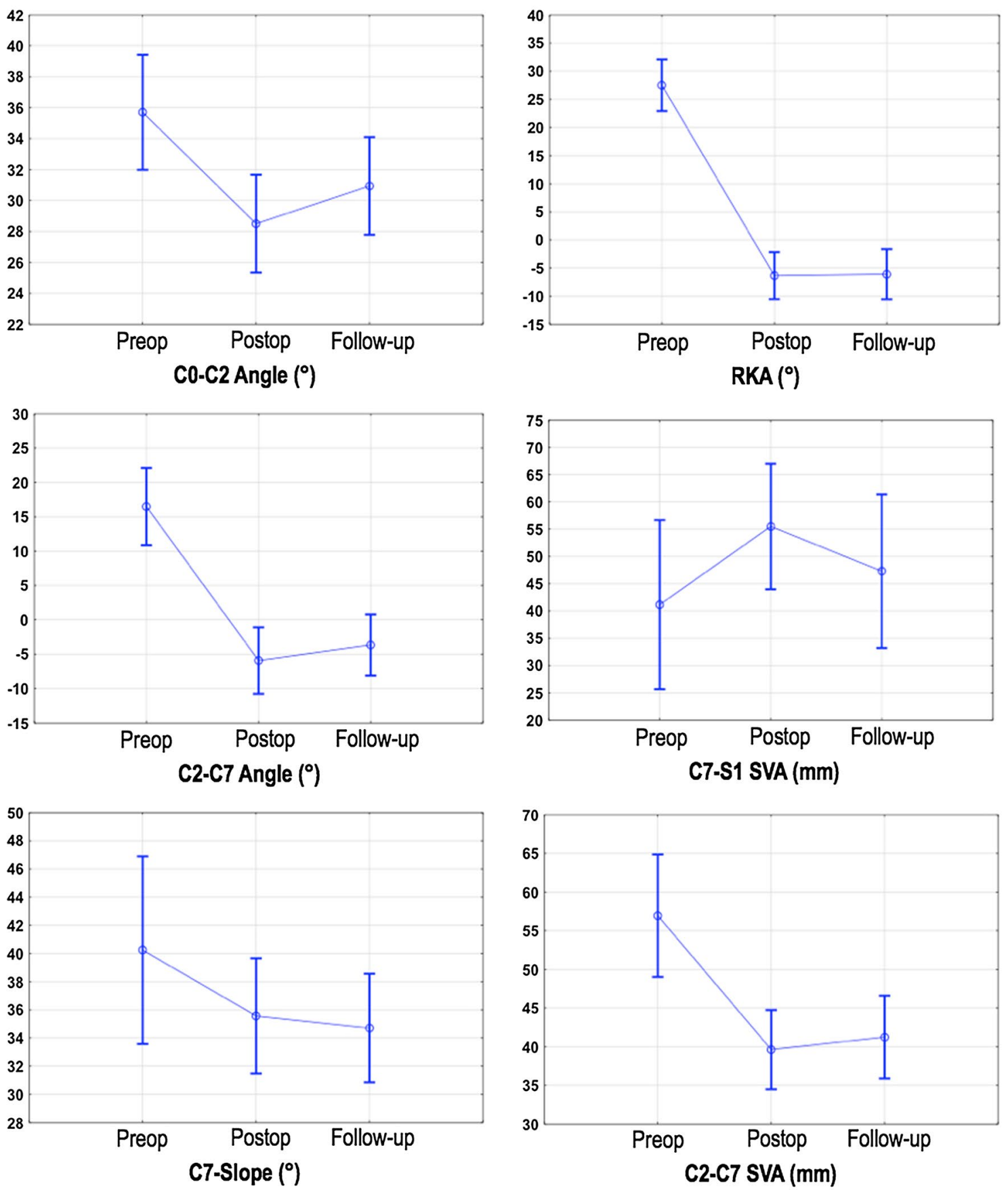

Fig. 6 Radiographic alignment results of 88 patients with rigid CK preop, postop and at follow-up. Radiographic results illustrating the postop compensatory changes in regions adjacent to the surgically corrected cervical kyphosis as presented by a change in the RKA.

Graphs show means with 1 standard deviation and 95\% confidence interval (CI). The $p$-level for differences among variables measured at different time points is listed in Table 4

The incidence of any type of wound-related complication treated either non-surgically or surgically was $14 \%$. Patients with a wound-related complication were more likely to experience DJK (50\% vs. 9\%, $p=.04$ ). The incidence of distal junctional failure (including screw pull-out, screw loosening,

vertebral fracture, implant failure, posterior element fracture) and/or advanced recurrent kyphosis was $13 \%$. 

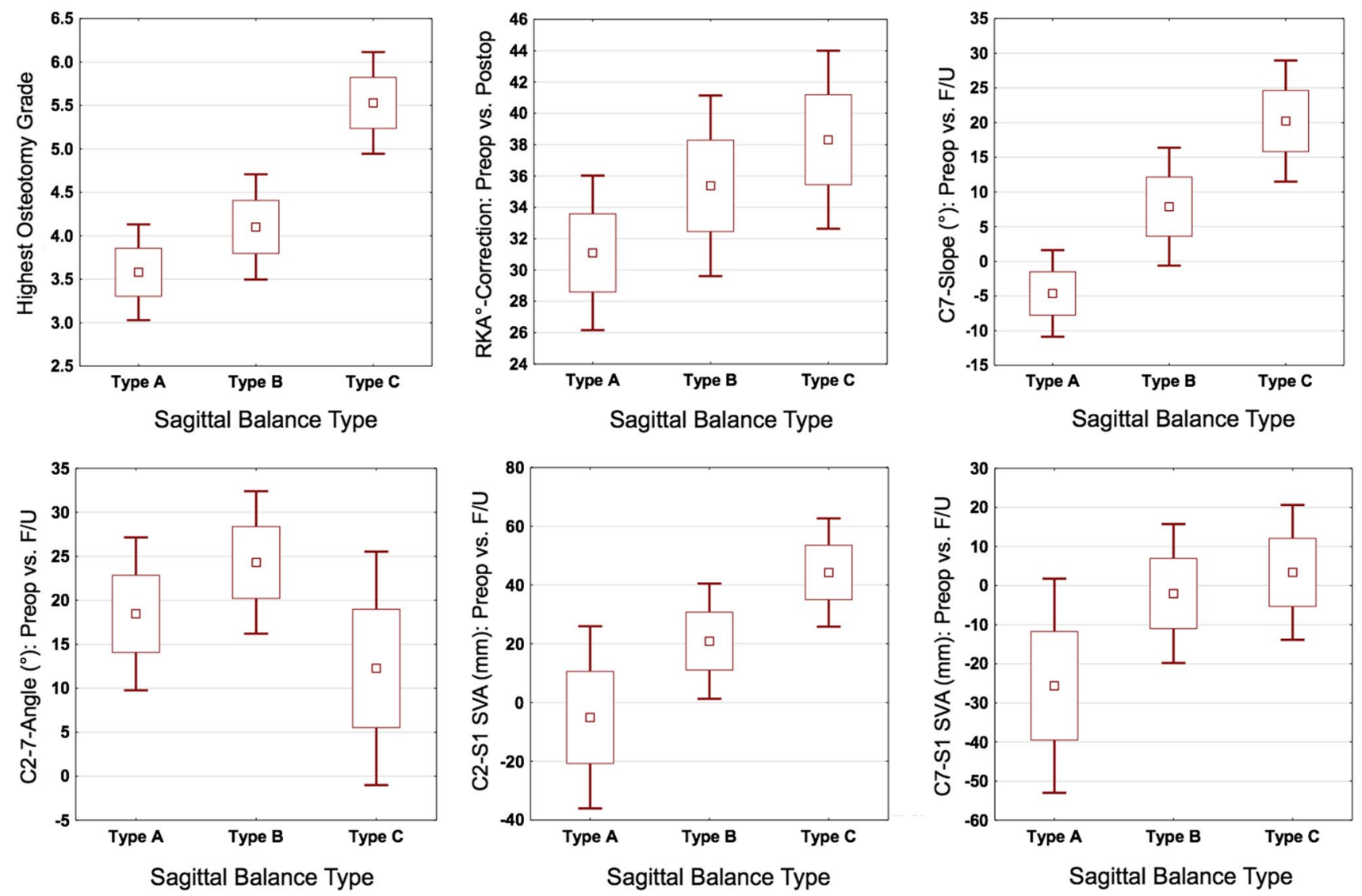

Mean $\square$ Mean + SD $\square$ Mean \pm 1.96 SD $工$

Fig. 7 Radiographic results according to different sagittal cervical balance types $(A-C)$. The postop changes in radiographic measures are illustrated in perspective of each sagittal balance type and in per-

\section{Discussion}

Information on the most appropriate treatment approach for each CK pattern is scant and requires individual consideration based on the underlying etiology. Likewise, a recent study on 71 patients with adult cervical deformity from 11 centres reported on 6 months follow-up [26]. Due to a limited number of studies, understanding of treatment effects in CK surgery is only slowly growing. The current study is one of the largest to focus on the surgical treatment of rigid CK and includes a multitude of etiologies. Sample characteristics regarding age, ASA-score, fusion levels, blood loss, and use of anterior and/or posterior and combined approaches were similar to previous studies on $\mathrm{CK}$ with a representative sample [1, 23, 27-31]. Our study was designed to address all facets of treating rigid $\mathrm{CK}$ and serves as a good basis to characterize future research needs. The main results will be discussed in the context of relevant literature.

Our study defined rigidity of CK on preop CT-scans in $97 \%$ of patients and is, thus, one of the first to differentiate spective of the highest selected osteotomy grade according to the Ames-classification. The $p$-levels for differences among sagittal balance types are reported in Table 3

into rigid, semi-rigid and flexible CK. Surgical invasiveness, the need for a surgical release and utilization of osteotomies is significantly increased in patients with rigid $\mathrm{CK}$ in comparison to semi-rigid and flexible CK. Accordingly, to compare the effect of each surgical approach and technique, CK flexibility must be reported in CK studies. In the majority of previous studies, the flexibility was not analysed [26-28]. One study reported on the correction of 21 patients with flexible $\mathrm{CK}$ and 12 patients with semi-rigid CK [32]. Another study used flexion-extension films to determine CK flexibility and for definition of 'fixed' CK [33]. In a study by O'Shaugnessy [34], the authors defined fixed CK as less than $50 \%$ reduction on dynamic flexion-extension films and by ankylosis on CT scan. By definition, $\mathrm{CK}$ is rigid in patients with OPLL [35] and ankylosing spondylitis (AS) $[36,37]$. In the current study, only patients with rigid $\mathrm{CK}$ with ankylosis on CT scans or motion $<2^{\circ}$ on flexion-extension films were studied.

In adult patients with cervical degeneration but a globally balanced spine, the sub-axial cervical spine was shown 
Table 5 Complications in corrective surgery for rigid CK in 88 patients

\begin{tabular}{|c|c|c|}
\hline Variable & Number $(\%)$ & Valids \\
\hline Any major long-term complication ${ }^{\mathrm{a}, * *}$ & $n=23(26.7 \%)$ & $n=86$ \\
\hline Instrumentation failure & $n=6$ & \\
\hline Wound-dehiscence indicating revision surgery & $n=5$ & \\
\hline Distal junctional kyphosis or failure & $n=4$ & \\
\hline Death by PVT, postop cardiopulmonary decompensation or unrelated cause & $n=3$ & \\
\hline Lasting postop $\mathrm{MRC} \leq 3$ & $n=2$ & \\
\hline Tumour recurrence & $n=1$ & \\
\hline Myelopathic neurologic worsening & $n=1$ & \\
\hline Cerebral infarction due to carotid artery stenosis & $n=1$ & \\
\hline Worsening of arm function in a patient with congenital spasticity & $n=1$ & \\
\hline Any minor long-term complication ${ }^{\mathrm{a}}$ & $n=13(15.3 \%)$ & $n=85$ \\
\hline Mild nerve root irritation of $\mathrm{C} 8$ & $n=4$ & \\
\hline Deep-fascial painful dehiscence & $n=2$ & \\
\hline Unilateral reccurent nerve palsy & $n=1$ & \\
\hline DJK due to osteoporotic T9\# & $n=1$ & \\
\hline Mild progressive re-kyphosis $\mathrm{C} 2-7$ & $n=2$ & \\
\hline Mild to moderate dysphagia & $n=2$ & \\
\hline Anterior screw tip prominence & $n=1$ & \\
\hline Revision surgery ${ }^{\mathrm{b}}$ & $n=22(25.9 \%)$ & $n=85$ \\
\hline \multicolumn{3}{|l|}{ Indications for revision } \\
\hline Wound-related (wound and fascial dehiscene, prominent implants, haematoma collection or infection) & $n=12$ & \\
\hline Surgery for tumour recurrence & $n=1$ & \\
\hline Reinstrumentation and fusion (with/without realignment surgery) & $n=10$ & \\
\hline Re-decompression & $n=3$ & \\
\hline Any immediate postop complication ${ }^{\mathrm{a}}$ & $n=38(43.2 \%)$ & $n=88$ \\
\hline Sensitive cervical root irritation not indicating revision & $n=4$ & \\
\hline $\begin{array}{l}\text { Significant dysphagia requiring treatment (e.g. medical treatment, placement of nasogastric tube, PEG, reintubation, } \\
\text { prolonged ventilation, tracheostomy) }\end{array}$ & $n=12$ & \\
\hline Cardiopulmonary decompensation & $n=3$ & \\
\hline Postop in hospital death & $n=1$ & \\
\hline Acute deep or superficial wound-breakdown, dehiscence, haematoma with/without wound infection & $n=6$ & \\
\hline $\begin{array}{l}\text { Bilateral progressive ulnary nerve irritation due to nerve entrapment by an uncommon course of anconeus muscle } \\
\text { (responding to surgical release) }\end{array}$ & $n=1$ & \\
\hline Non-fatal pulmonary embolism & $n=1$ & \\
\hline Postop delirium & $n=1$ & \\
\hline Construct instability at osteotomy site indicating additional ACDFP & $n=1$ & \\
\hline Post-operative segmental motor deficit (palsy); $\mathrm{MRC} \leq 4$ & $n=18(20.9 \%)$ & $n=86$ \\
\hline Postop segmental motor deficit $\mathrm{MRC} \leq 3$ & $n=14$ & \\
\hline Postop worst MRC-grade & $3 \pm 1(1-4)$ & \\
\hline Follow-up worst MRC-grade & $4.5 \pm(2-5)$ & \\
\hline Post-operative nerve root irritation (motoric or sensitive) & $n=22(25 \%)$ & $n=87$ \\
\hline \multicolumn{3}{|l|}{ Involved cervical root levels* } \\
\hline C5 & $n=7(8 \%)$ & \\
\hline C6 & $n=5(5.7 \%)$ & \\
\hline $\mathrm{C} 7$ & $n=5(5.7 \%)$ & \\
\hline $\mathrm{C} 8$ & $n=9(10.3 \%)$ & \\
\hline Bilateral versus unilateral & $\begin{array}{l}n=6(27.3 \%) \text { versus } n=16 \\
\quad(72.7 \%)\end{array}$ & \\
\hline
\end{tabular}

$M R C$ medical research council grading, $N F 1$ neurofibromatosis type $1, P E G$ percutaneous endoscopic gastrostomy, $P V T$ pulmonary vein thrombolism

*Multiple nerve roots can be involved; **Overlap of instrumentation failure and DJK

${ }^{\text {a } P a t i e n t s ~ c a n ~ h a v e ~ m u l t i p l e ~ c o m p l i c a t i o n s ~}$

${ }^{\mathrm{b}}$ Patients can have multiple indications for revision surgery 
to reveal different alignment patterns including a global kyphotic cervical spine as well as straight, sigmoid, and reverse sigmoid curve patterns [21]. The CSRS-E classification of sagittal balance types among patients with rigid CK showed that substantial clinical and radiographic differences exist according to each type. The surgical approach selected varied significantly among types as well as osteotomy types, fusion length, and number of patients with LIV $>\mathrm{T} 2$ and CSM. Patients with different sagittal balance types had significantly different preop deformity parameters and had different correction geometries with different postop alignment changes. These findings indicate that in future studies, outcomes and complications as well as technique- and strategyrelated results should not only be differentiated according to $\mathrm{CK}$ rigidity but also to the sagittal cervical balance type.

\section{Surgical and clinical results}

Blood and fluid-volume management can pose significant challenges during lengthy and invasive cervical spine surgeries [38]. This is particularly true in CK surgery. In our study, blood loss was shown to be closely related to the invasiveness of the procedure in terms of surgical time, osteotomy grade, extent of surgical deformity correction, and clinical factors such as ASA-scores. Blood loss correlated with complication occurrence. In a study by Kim [28] the authors reported on increased blood loss with cervical CWO in comparison to other osteotomy techniques. In a recent study by Koller [39] on 91 patients with cervicothoracic fusions, blood loss significantly correlated with BMI and etiology of CK. AS patients had increased blood loss. This was not the case in our study and might be related to a broader spectrum of etiologies and age ranges included as well as differences in the rate of revision surgery at index treatment which was $63 \%$ [40] versus $28 \%$ in the current study.

Several studies have identified a correlation between the correction of CK and improved neck pain and disability. In a study by Kim [28] on 61 CK patients with 2.5 years followup preop NDI significantly improved from 34 to 22 . In a study by Theologis [1] on $10 \mathrm{CK}$ patients, NDI improved significantly from 54.5 to 42.6 . Other authors also reported an improvement of neck pain and disability after correction of CK [9, 41, 42]. In those patients in our study with clinical outcome data available, improvement of disability and pain was related to CK-correction. Of note, patients with better deformity correction and less residual deformity had better clinical outcome measures at last follow-up. Patients with major complications had worse NDI scores at follow-up. These findings are in line with prior studies that reported a positive correlation between clinical outcomes and reduction of cervical deformity, and worse outcomes in patients with revision surgery $[1,3-5,43]$.

\section{Radiographic results}

\section{Surgical kyphosis correction}

The current study enabled the analysis of geometric changes following surgery in 88 patients with rigid CK. The highest osteotomy grade selected by the surgeon rather than the surgical approach had a main influence on the degree of RKA-correction. Statistical analysis revealed that with increasing osteotomy grade the deformity correction could also be increased. As a consequence, the severity of SVT increased with the degree of deformity correction and was higher in patients with angular versus arcuary shaped CK. This information indicates special considerations to prevent intraoperative SVT in patients with intended large corrections and angular deformity.

Our average correction was $34^{\circ}$ and significant postop correction was shown for all cervical deformity measures. Comparison of patients with $3 \mathrm{CO}$ and without $3 \mathrm{CO}$ showed a significantly different RKA-correction of $37^{\circ}\left( \pm 15^{\circ}\right)$ and $31^{\circ}\left( \pm 16^{\circ}\right)$. One has to consider that the wide range for correction reflects the different surgeons' targets for each individual case and the feasibility of achieving that correction during surgery.

These results compare well with previous studies published on the correction on rigid CK. Regional radiographic correction reported averaged $20^{\circ}-25^{\circ}$ in a series on OWO [44] with average $37^{\circ} \mathrm{CVBA}-$ correction [37]. Mehdian [45] reported on CBVA-angle correction of $47^{\circ}$ in a series of 12 AS patients using OWO. Deviren [41] reported a mean correction of $49^{\circ}$ and improvement of C2-7 SVA by $4.5 \mathrm{~cm}$ in 11 patients undergoing $\mathrm{C} 7$ or T1 CWO. In a series of 8 patients by Samudrala [46], correction averaged $36^{\circ}$, and $57^{\circ}$ in a series of 8 patients by Tokala [47]. Lee [48] reported on 7 patients that had $3 \mathrm{CO}, 5$ with $\mathrm{CWO}$ and two who had combined approaches. $\mathrm{CWO}$ was at $\mathrm{C} 7$ and $\mathrm{C} 6$, and mean correction was $40^{\circ}$. In a series on 48 patients with cervical or upper thoracic $3 \mathrm{CO}$ by Theologis [1] correction of $\mathrm{C} 2-\mathrm{T} 1$ angle was $26^{\circ}-44^{\circ}$ and C2-C7 SVA $3.8-1.7 \mathrm{~cm}$. In a series of 16 patients by O'Shaughnessy [34] with 'fixed' CK treated with $3 \mathrm{CO}$ using an antero-posterior strategy, mean correction angle was $48^{\circ}$. Kim [28] analysed the results of $61 \mathrm{CK}$ patients including rigid and non-rigid CK. With OWO, mean CK-correction and C2-C7 SVA change was $10^{\circ}$ and $1.8 \mathrm{~cm}$, with CWO $34.5^{\circ}$ and $2.5 \mathrm{~cm}$, with combined anterior release and posterior correction $17^{\circ}$ and $1 \mathrm{~cm}$, and with anterior release and posterior correction applying an OWO-mechanismn $28^{\circ}$ and $3 \mathrm{~cm}$, respectively. In another analysis on 23 patients [20], correction of CK and SVA averaged $19^{\circ}$ and $40 \mathrm{~mm}$ without differences among different $3 \mathrm{CO}$ types. SVT averaged $17 \%$. The current study did not find differences among 3CO techniques because the 3CO type usually is not the limiting factor for maximum CK-correction. Rather 
patient and strategic factors influence the strategy and osteotomy type selected including the feasibility of the approach, patient age and comorbidities, previous surgeries, a clinical rationale balancing neurologic risks with surgical possibilities, concerns on post-decompression stability and surgical invasiveness. The surgical target angle takes into account whether the goals discussed with the patient are to restore radiographic alignment towards normalcy, to improve CK in order to address the spinal cord being draped over the kyphotic apex, to improve visual axis, and/or to translate the centre of gravity of the head posteriorly to unload painfully fatigued posterior neck muscles. Therefore, further analysis of the maximum CK-correction achieved with different approaches or with different osteotomy types was not done in the present study.

\section{Cervical spinal alignment changes and balance}

Analysis of radiographic variables over time showed a significant interdependency of regional alignment changes at the level of correction and the adjacent mobile cervical regions, e.g. at $\mathrm{C} 0-\mathrm{C} 2$ or the thoracic spine represented by the $\mathrm{C} 7 \mathrm{~S}$. For patients with rigid CK our study confirmed the strong physiologic interdependencies between the craniocervical, cervical, cervicothoracic, and thoracolumbar spinal alignment as observed in healthy subjects [49-54]. In a study on 145 healthy or operated patients [50] the authors showed significant correlations between the upper and lower cervical regions and the thoracic spine (C7S). No significantly different correlation strengths were found among asymptomatic, symptomatic, and surgically treated patients. The C7S was shown to be a useful marker of overall sagittal truncal alignment, acting as a link between the occipito-cervical and thoracolumbar spine. Another study, limited to the cervical region, confirmed these observations following correction of flexible CK and showed strong interdependencies among cervical levels preop and postop [55]. In our study on rigid CK, the physiologic interdependencies between spinal regions could also be differentiated according to the sagittal cervical balance type. This analysis stressed the geometric differences among types in regard to postop alignment changes (Fig. 5). The study also demonstrated significant interdependencies between alignment changes of the cervical and thoracolumbar spine as well as between regional cervical spinal alignment changes and measures of cervical balance (e.g. AP translation of C2-C7 SVA) and global measures of trunk balance (e.g. AP translation of $\mathrm{C} 2-\mathrm{S} 1$ SVA and C7-S1 SVA).

Following CK-correction reciprocal changes with an increase of thoracic kyphosis and decrease of T1- and C7-slope can be observed if patients have a flexible thoracic spine [56]. In patients with CK revealing both preop spinal and pelvic compensation, postop spino-pelvic reciprocal changes can be observed as well $[20,57,58]$. In a recent study with 45 patients showing a cervical or cervicothoracic driver of their deformity, Passias [26] reported that patients operated at cervical driver levels showed concomitantly increased postop thoracic kyphosis and T1-slope [26]. In another study by Lee [56] on 54 patients with mild $\mathrm{CK}$ and $\geq 2$-level fusion, increased postop $\mathrm{C} 2-\mathrm{C} 7$ lordosis correlated with a decreased lordosis of $\mathrm{C} 0-\mathrm{C} 2$ as well as a significantly increased thoracic kyphosis and T1-slope, while lumbo-pelvic parameters were not changed in lieu of only mild deformities operated. In a study from Ramchandran [58] improvement of cervical alignment in 75 patients with fusion within $\mathrm{C} 2-\mathrm{T} 4$ was accompanied by an increase of thoracic kyphosis and C7-S1 SVA, while a decrease of $\mathrm{C} 0-\mathrm{C} 2$ angle was noted. No change was noted in thoracolumbar and lumbo-pelvic variables. If osteotomy correction includes the cervicothoracic junction, the postop changes of $\mathrm{C} 7$ and $\mathrm{T} 1$ slope and thoracic kyphosis differ: In a study by Smith [30] on 23 CK patients with both cervical and upper thoracic 3CO, the authors noted an average decrease of T1-slope while thoracic kyphosis was maintained and C7-S1 SVA slightly decreased. Lumbo-pelvic measures did not change. In a study by Theologis [1] on 48 patients, T1-slope only slightly improved following cervical osteotomy while significant improvement was noted for patients with upper thoracic 3CO. Global alignment defined by the C7-S1 significantly improved only in patients with upper thoracic $3 \mathrm{CO}$.

The findings of Theologis [1] and Smith [30] echo those of the current study. Here, several patients showed postop improvement of both cervical compensatory alignment, such as at $\mathrm{C} 0-\mathrm{C} 2$, and thoracic kyphosis (C7S) (Fig. 6) as a consequence of a) postop immediate change of $\mathrm{C} 7$ and T1-slope in patients with cervicothoracic osteotomy or b) by relaxation of the infra-cervical compensatory alignment CK patients recruit in an effort to maintain horizontal gaze and global standing alignment [58]. The findings of significant interdependencies of regional cervical and global truncal alignment changes in rigid CK are striking. First, several patients had multilevel cervicothoracic fusions averaging 7.6 levels, reaching the thoracic spine proximally and leaving only $\mathrm{C} 0-2$ mobile. Second, several patients had stiff thoracolumbar spines (e.g. patients with AS and patients with prior thoracolumbar fusions, see Table 1) resulting in a limited postop ability for compensatory changes in the thoracolumbar spine and, thus, a limited chance to influence the C2-S1 SVA, C7-S1 SVA and C7S measures by active thoracolumbar adjustments.

It remains difficult to predict whether patients will achieve a postop global balance with the head centre of gravity and C2-SVA balanced over the trunk or if only the trunk will be balanced, but the C2-C7 SVA is still translated far anteriorly [59]. Pelvic and lower limb compensation mechanisms 
can take part in adjustments for nuances of residual sagittal imbalance following CK surgeries [20] as it was seen also in CK patients operated in the current study, though we could not collect pelvic parameters. We observed, however, a postop correction of regional cervical balance in terms of a reduction of C2-C7 SVA (and C2-S1 SVA) and accompanied by a reversal increase of the C7-S1 SVA with moderate improvement of C7-S1 until last follow-up (Fig. 6). Changes of the C7-S1 SVA are mediated by thoracic, lumbar or pelvic adjustments. Our findings suggest that significant correction of severe $\mathrm{CK}$ as in the current sample causes changes of the truncal alignment and relocation from a prior compensatory alignment. Postop difficulties were observed in CK patients to adjust global balance following an immediate and significant CK-correction, but this condition improved over time. Likewise, changes over time were also seen in our patients. Correction of cervical deformity was not found to correlate with surgical approach or traction strategies. However, CK-correction was improved in patients with higher osteotomy grades. The latter group included 3-column osteotomies (e.g. CWO/OWO, grades 4-6 according to the Ames-classification). These osteotomies are usually located at or close to the cervicothoracic junction below the level of the vertebral artery [60], though some $3 \mathrm{CO}$ were done as part of a $360^{\circ}$-approach in CK patients with compression of the spinal cord being draped over the apex at C2-7 levels. The more caudal the osteotomy position is, the greater is its impact on posterior translation of C2-7 SVA and, thus, relocating the head centre of gravity over the trunk [14, 20]. In our study, patients with $3 \mathrm{CO}$ showed a significantly different correction of C2-C7 SVA with an average $27 \mathrm{~mm}$ compared to patients without $3 \mathrm{CO}$ showing a change of C2-7 SVA of average $7 \mathrm{~mm}$. Findings are in line with a study on 48 patients that had $3 \mathrm{CO}$ in the lower cervical or upper thoracic spine [1]. Postop mean change for C2-C7 was SVA $38 \mathrm{~mm}$ versus $17 \mathrm{~mm}$. The more caudal thoracic $3 \mathrm{CO}$ had a larger effect on restoration of sagittal balance.

SVT at the osteotomy site can cause instability and poses a risk for neurologic structures [28, 44, 45, 61, 62] and was observed in $27-44 \%$ in previous CK studies [20, 44, 63]. SVT is the result of advanced correction, eccentric force application, non-physiologic angulation, and the difficulty to concentrate corrective forces at a single COR [20]. In a recent study on 53 patients that had $3 \mathrm{CO}$ for rigid CK, Koller [20] established an analysis of Center of Rotation (COR) location in 23 patients and showed that a significant mismatch between conceptional and actual osteotomy COR existed. The actual COR was far off the conceptional COR. These findings added evidence to understanding of SVT in patients with CK surgery. In the current study, SVT correlated with the degree of deformity correction. It also correlated with occurrence of major complications and postop segmental motor deficits. These observations stress that SVT control during correction remains an important goal and a field of research.

\section{Complications}

Surgical correction of rigid adult thoracolumbar deformities [64] and CK is challenged by the potential for a significant number of complications. In cervical deformity surgery, major complications were reported in $24-60 \%$ including neurologic complications in 7-25\% [1, 44, 65]. Complication rates with cervical $3 \mathrm{CO}$ can be as high as $60 \%$ with reoperation rates of $33 \%$ [1] and the rate of severe neurologic deficits can be as high as $17-19 \%[1,44]$.

In a retrospective study on 23 patients from 13 centres with cervicothoracic and upper thoracic $3 \mathrm{CO}$, the incidence of major complications was $52 \%$ with $39 \%$ of patients being affected [30], 22\% had neurological root-related major complications. In a study of Langeloo [66] revision surgery was indicated in $13 \%$. In another series on 48 patients from two centres [1] with cervicothoracic and upper thoracic 3CO, reoperation rates were $33 \%$ for lower cervical and $18 \%$ for upper thoracic $3 \mathrm{CO} .6 \%$ of patients had infection and neurologic deficits requiring revision surgery. $8 \%$ of patients required revision for non-union. In the current study, the authors analysed whether the correction technique, approach strategy or osteotomy type influences perioperative complications. Immediate post-operative complications were common (43\%) and increased with age, BMI, the POV-Group, surgery time, ASA-score, blood loss, with LIV $>$ T2, and with higher preop sagittal plane deformity. Defined as an immediate postop complication, postop segmental motor deficits were studied and, notably, osteotomy type and grade as well as DAR had no significant influence. However, in the POV-Group there was an increased risk for occurrence of a segmental motor deficit. The MRC-grade correlated with age and the degree of deformity correction and particularly postop SVT. Most patients with postop segmental motor deficits recovered; however, the potential for permanent injury exists. Root-specific complications due to iatrogenic stenosis as a consequence of extension osteotomy closure, infolding scar tissue, and SVT were also frequently observed in the past during CK-correction in AS patients [44, 67].

In our study one patient deteriorated permanent by one ASIA grade and at follow-up MRC-grades averaged 4.5 and only two patients had MRC $\leq 3$. Comparison of neurologic complications in studies with CK-correction using modern instrumentation is difficult because there are few large series available $[44,68,69]$. In three reviews focused on AS patients, the sample sizes were $188-286,19-23 \%$ of patients had neurologic complications mostly in the form of a transient C8-radiculopathy, and 3-4\% had permanent spinal cord deficits. Kurakawa [70], Nakashima [71], Hojo [72] and Blizzard [73] reported an increased rate of C5-palsy 
with increasing CK-correction without preventive foraminotomy. In a series of 16 patients that underwent circumferential release and 3CO, 19\% had postop temporary C5-palsy [34]. Using modern screw-rod constructs in 16 AS patients with rigid $\mathrm{CK}$ undergoing $3 \mathrm{CO}$, Langeloo [66] reported that 10 patients $(63 \%)$ had some type of neurologic deficit, 9 had C8-paresthesia, 1 developed a spinal cord deficit. In the study by Samudrala [42], 3 of 8 patients (38\%) with $3 \mathrm{CO}$ for rigid CK had postop neurologic deficits in terms of rootrelated pain or decrease in motor function. In a study by Tokala [47] 3 of 8 patients with $3 \mathrm{CO}$ had transient C8-rootrelated deficit. Other small series with posterior 3CO [48] or combined approaches [27, 28, 33] did not observe neurologic deficits.

In the current study intraoperative neuromonitoring (IONM) was used in $67 \%$ of cases. Similar to a case reported by Park [74] postop new root palsies could not be completely prevented using IONM. The reasons for an overall low rate of permanent neurologic complications might be related to the experience in CK-correction of surgeons participating in this study. Park [74] and Mummanei [33] showed that IONM can influence decision making in CK-correction due to intraoperative alerts. The surgeons in the current study share this experience and, thus, IONM is considered an important instrument in CK-correction.

The incidence of major long-term complications (22\%) in our study increased with surgical time, in smokers, and with larger preop RKA, deformity correction, and SVT. The need for revision surgery in cervicothoracic fusions can be as high as 9\%-33\% [1, 31, 40, 65]. In our study the revision rate was $26 \%$ emphasizing that not all major complications necessitated revision surgery. The risk for a revision was elevated in the POV-Group, in smokers, and greater deformity correction. Patients with revision had a significantly greater increase of the DJK-angle and a larger residual deformity in terms of postop C7S, SVT, and DJK-angle.

Distal junctional failure was an indication for revision in $13 \%$ of patients and resembles a known challenge in long fusions crossing the cervicothoracic junction, particularly in elderly patients. Residual deformity in adult thoracolumbar deformity is frequent, about one-third of patients on average [75-80]. In cervical deformity surgery, $46 \%$ of patients were reported to have failed radiographic outcomes if a 'physiologic' cervical SVA was defined as surgical target [81]. With residual imbalance, there is a significantly increased risk of construct failure, delayed union, and loss of correction [75, 80-84]. In a study on 71 patients with cervical deformity $[29,81]$, a multivariate regression analysis revealed that the occurrence of post-operative DJK was the only significant parameter associated with suboptimal outcomes in respect to correction of C2-C7 SVA. A larger thoracic inclination (T1-slope) was related to significantly increased rates of DJK (29\% vs. 1\%). In another analysis [29] on 101 patients,
$24 \%$ of patients met criteria for DJK and $6 \%$ needed revision surgery. Baseline radiographic parameters were identified as strongest predictors for DJK. Patients with bigger preop deformity are prone to reveal residual postop deformity and, thus, increased stress at the distal fusion levels where DJK occurs. A recent study [39] on 91 patients with posterior cervicothoracic fusion reported mechanical construct failure in $23 \%$ of patients and $37 \%$ of patients needed revision surgery. Main diagnosis for revision was DJK (79\% of revised patients). The study had a heterogenic patient group including patients with or without CK-correction. The risk for mechanical failure, wound-related complications, and revision surgery increased in patients with rheumatoid or syndrome-related spinal disease (e.g. our POV-Group) as well as in patients with lower pedicle screw accuracy at the LIV. The risk for revision surgery was significantly related to the degree of preop deformity (C2-C7 SVA and C7S) and it was significantly lower in patients who had undergone a CK- correction using, e.g. 3CO as well as in patients with better postop sagittal balance [20]. In a study on 135 patients with cervicothoracic fusions, Yang [85] reported a pseudarthrosis rate of $7 \%$ and the risk increased in patients with lack of anterior support, longer fusion, and tobacco use. In a study by Hirano [86] on 56 rheumatoid patients (e.g. our POV-Group) and long occipito-thoracic fusions, each $20 \%$ experienced distal junctional compression fractures at the LIV or implant failure with revision surgery in $16 \%$. In a similar study by Tanouchi [87] $26 \%$ of patients suffered distal junctional fractures and this rate was increased in patients fused to T1-T3 versus T4-T7. In our study, of 11 patients with distal junctional kyphosis or failure, 8 patients (72\%) had LIV > T2. Statistical analysis showed that patients with increased DJK-angle, increased C7S, the POV-Group, and smokers had increased risk for revision surgery. In perspective of the literature, our findings add evidence to the assumption that long fusions crossing the cervicothoracic spine, ending in the upper thoracic region, docking in poor bone and in a spine with residual global imbalance, have an increased risk for distal failure and revision surgery.

Finally, fusion following revision surgery was achieved in all patients in the current series at follow-up. The risk for wound-related complication was $14 \%$ and occurred only with the posterior approach. In another series [39] any kind of wound-related complication with a posterior cervicothoracic approach was noted in $52 \%$ of patients, if patients with deep-fascial dehiscence were also included. Prior studies have shown an increased risk for wound-related complications such as wound-dehiscence and infection with posterior compared to anterior approaches $[88,89]$ in the range from $3 \%$ [85], $6 \%$ [90], $10 \%$ [91] to $14 \%$ [86] in cervicothoracic surgeries and 7\% [33], $12.5 \%$ [66] to $25 \%$ [47] in CK surgery. 
In long complex surgeries for CK-correction, pulmonary dysfunction and fluid-shift related anaesthesiologic complications can cause a significant delay of postop reconvalescence and can contribute to the occurrence of wound-related complications. The duration of ventilation averaged 0.4 days with a wide range from 0-7 days. Theologis [44] reported on $20 \%$ of patients needing tracheostomy following cervical $3 \mathrm{CO}$ and 10 days of intensive care unit stay. In O'Shaugnessy's study [34] on 16 patients, $19 \%$ had tracheostomy and prolonged ventilation. Mummaneni [33] reported on 13\% of patients necessitating PEG/tracheostomy placement. In another series on 20 patients with long cervicothoracic fusions, $45 \%$ experienced airway oedema requiring extended intubation or reintubation [92]. Likewise, pulmonary complications and prolonged ventilation in up to $25 \%$ of patients resembled the majority of complications in a subgroup of elderly patients that had long cervicothoracic fusion [31]. Notably, in another series on CKcorrections the need for tracheostomy placement was 0\% [20]. Those authors [20] and others [92, 93] stress that advancements towards a combined approach of surgeons and anaesthesiologists towards a deformity oriented anaesthesiologic care, including restricted fluid-volume and blood management protocols, can reduce the rate of postop wound-related and medical complications.

In the current study, two patients died as a result of surgery related medical reasons and one patient due unrelated causes. Morbidity and mortality rates are similar to other studies reporting on long cervicothoracic fusions [31] and those of prior reviews on CK-correction [16, 44, 66, 68, 69, 94].

\section{Limitations and conclusions}

The study shares limitations with other retrospective studies on CK-treatment due to its retrospective nature with limited access to preop and postop clinical and complications data making complication data particularly subject to recall bias. Prospective studies on adult deformity surgeries [64] have shown increased rates of complications if compared to retrospective series. The current study identified several risk factors for complications and revision surgery. Future prospective study designs might delineate the independent drivers of perioperative complications and revision surgery. Though limited in its retrospective character, several new observations could be explored in a large sample of an otherwise rare pathology, namely rigid $\mathrm{CK}$.

This study serves as an excellent basis for future prospective studies as it outlines those variables, surgical characteristics and alignment variables of major interest in the research on CK.

Acknowledgements Open access funding provided by Paracelsus Medical University. Alan Leonard (secretary of the CSRS-Europe) for important support at all times of the study project. All authors and respective supporters in participating clinical sites. All members of the CSRS who supported this project.

\section{Compliance with ethical standards}

Conflict of interest The authors declare that they have no conflict of interest.

Open Access This article is distributed under the terms of the Creative Commons Attribution 4.0 International License (http://creativeco mmons.org/licenses/by/4.0/), which permits unrestricted use, distribution, and reproduction in any medium, provided you give appropriate credit to the original author(s) and the source, provide a link to the Creative Commons license, and indicate if changes were made.

\section{References}

1. Theologis AA, Tabaraee E, Funao H, Smith JS, Bruch S, Tay B, Kebaish K, Deviren V, Ames C (2015) Three-column osteotomies of the lower cervical and upper thoracic spine: comparison of early outcomes, radiographic parameters, and peri-operative compliations in 48 patients. Eur Spine J 24(Suppl 1):S23-S30

2. Ames C, Smith JS, Eastlack R, Blaskiewicz JD, Shaffrey CI et al (2015) Reliability assessment of a novel cervical spine deformity classification system. J Neurosurg Spine 23:673-683

3. Grosso MJ, Hwang R, Mroz T, Benzel E, Steinmetz MP (2013) Relationship between degree of focal kyphosis correction and neurological outcomes for patients undergoing cervical deformity correction surgery. J Neurosurg Spine 18:537-544

4. Roguski M, Benzel EC, Curran JN, Magge SN, Bisson EF et al (2014) Postoperative cervical sagittal imbalance negatively affects outcomes after surgery for cervical spondylotic myelopathy. Spine 39:2070-2077

5. Shamji MF, Mohanty C, Massicotte EM, Fehlings MG (2016) The association of cervical spine alignment with neurologic recovery in a prospective cohort of patients with surgical myelopathy: analysis of a series of 124 cases. World Neurosurg 86:112-119

6. Iyer S, Nemani V, Nguyen J, Elysee J, Burapachaisri A, Ames CP, Kim JH (2016) Impact of cervical sagittal alignment parameters on neck disability. Spine 41:371-377

7. Hyun S-J, Kim K-J, Jahng T-A, Kim H-J (2016) Relationship between $\mathrm{T} 1$ slope and cervical alignment following multilevel posterior cervical fusion surgery. Spine 41:E396-E402

8. Qian J, Qiu Y, Qian B-P, Zhu Z-Z, Wang B, Yu Y (2016) Compensatory modulation for severe global sagittal imbalance: significance of cervical compensation on quality of life in thoracolumbar kyphosis secondary to ankylosing spondyliti. Eur Spine J 25(11):3715-3722

9. Tang JA, Scheer JK, Smith JS, Deviren V, Bess S, Hart RA, Lafage V, Shaffrey CI, Schwab F, Ames CP, ISSG (2015) The impact of standing regional cervical sagittal alignment on outcomes in posterior cervical fusion surgery. Neurosurgery 71:662-669

10. Oe H, Togawa D, Nakai K, Yamada T, Arima H et al (2015) The influence of age and sex on cervical spinal alignment among volunteers aged over 50. Spine 40:1487-1494

11. Scheer JK, Protopsaltis TS, Terran JS, Smith JS, Hamilton DK, Kim HJ, Mundis GM Jr, Hart RA, McCarthy IM, Klineberg E, Lafage V, Bess S, Schwab F, Shaffrey CI, Ames CP; International Spine Study Group (2015) How the neck affects the back: changes in regional cervical sagittal alignment correlate to HRQOL improvement in adult thoracolumbar deformity patients at 2-year follow-up. J Neurosurg Spine 23:153-158 
12. Tang JA, Scheer JK, Smith JS, Acosta FL, Themistocles SP, Blonderl B, Bess S, Shaffrey CI, Deviren V, Lafage V, Schwab F, Ames CP, ISSG (2013) Cervical spine alignment, sagittal deformity, and clinical implications. J Neurosurg Spine 19:141-159

13. Chavanne A, Pettigrew DB, Holtz JR, Dollin N, Kuntz C 4th (2012) Spinal cord intramedullary pressure in cervical kyphotic deformity: a cadaveric study. Spine 36:1619-1629

14. Patwardhan AG, Havey RM, Khayatzadeh S, Muriuki MG, Voronov LI, Carandang G et al (2015) Postural consequences of cervical sagittal imbalance-a novel laboratory model. Spine 40:783-792

15. Patwardhan AG, Khayatzadeh S, Nguyen N-L, Havey RM, Li Voronov et al (2016) Is cervical sagittal imbalance a risk factor for adjacent segment pathomechanics after multilevel fusion? Spine 41:E580-E588

16. Ferch RD, Amjad Shad, Cadoux-Hudson TAD, Teddy PJ (2004) Anterior correction of cervical kyphotic deformity: effects on myelopathy, neck pain, and sagittal alignement. J Neurosurg (Spine 1) 100:13-19

17. Shimizu K, Nakamura M, Nishikawa Y, Hijikata S, Chiba K, Toyama Y (2005) Spinal kyphosis causes demyelination and neuronal loss in the spinal cord: a new model of kyphotic deformity using juvenile Japanese small game fowls. Spine 30:2388-2392

18. Nouri A, Kato S, Wu D, Nori S, Tetreault L, Fehlings MG (2018) Impact of cervical spine deformity on preoperative disease severity and postoperative outcomes following fusion surgery for degenerative cervical myelopathy: sub-analysis of AOSpine North America and international studies. Spine 43:248-254

19. Steinmetz MP, Stewart TJ, Kager CD, Benzel EC, Vaccaro AR (2007) Cervical deformity correction. Neurosurgery 60(Suppl):S90-S97

20. Koller H, Koller J, Mayer M, Hempfing A, Hitzl W (2018) Osteotomies in ankylosing spondylitis: where, how many, and how much? Eur Spine J 27:70-100

21. Yu M, Zhao WK, Li M, Wang SB, Sun Y, Jiang L, Wei F, Liu XG, Zeng L, Liu ZJ (2015) Analysis of cervical and global spine alignment under Roussouly sagittal classification in Chinese cervical spondylotic patients and asymptomatic subjects. Eur Spine J 24:1265-1273

22. Iyer S, Lenke LG, Nemani VM, Fu M, Shifflett GD, Albert TJ, Sides BA, Metz LN, Cunningham ME, Kim HJ (2016) Variations in occipitocervical and cervicothoracic alignment parameters based on age: a prospective study of asymptomatic volunteers using full-body radiographs. Spine 41:1837-1844

23. Ames CP, Smith JS, Scheer JK, Shaffrey CI, Lafage V, Deviren V, Moal B, Protopsaltis T, Mummaneni PV, Mundis GM Jr, Hostin R, Klineberg E, Burton DC, Hart R, Bess S, Schwab FJ; International Spine Study Group (2013) A standardized nomenclature for cervical spine soft-tissue release and osteotomy for deformity correction: clinical article. J Neurosurg Spine 19:269-278

24. Theologis AA, Bellevue KD, Qamirani E, Ames CP, Deviren V (2017) Asymmetric C7 pedicle subtraction osteotomy for correction of rigid cervical coronal imbalance secondary to post-traumatic heterotopic ossification: a case report, description of a novel surgical technique, and literature review. Eur Spine J 26:141-145

25. Glassman SD, Berven S, Bridwell KH, Horton W, Dimar JR (2005) Correlation of radiographic parameters and clinical symptoms in adult scoliosis. Spine 30:682-688

26. Passias PG, Jalai CM, Lafage V, Lafage R, Protopsaltis T, Ramchandran S, Horn SR, Poorman GW, Gupta M, Hart RA, Deviren V, Soroceanu A, Smith JS, Schwab F, Shaffrey CI, Ames CP (2017) Primary drivers of adult cervical deformity: prevalence, variations in presentation, and effect of surgical treatment strategies on early postoperative alignment. Neurosurg Epub 1:9
27. Kim HJ, Piyaskulkaew C, Riew D (2014) Anterior cervical osteotomy for fixed cervical deformities. Spine 1751-1757:1751-1757

28. Kim HJ, Piyaskulkaew Riew D (2015) Comparison of smithpetersen osteotomy versus pedicle subtraction osteotomy versus anterior- posterior osteotomy types for the correction of cervical spine deformities. Spine 40:143-146

29. Passia P, Vasquez-Montes D, Poorman GW, Protopsaltis T, Horn S, ISSG (2017) Predictive model for distal junctional kyphosis after cervical deformity surgery. In: 33rd CSRS-Europe Annual Meeting Salzburg, Austria

30. Smith JS, Shaffrey CI, Lafage R, Lafage V, Schwab FJ, Kim HJ, Scheer JK, Protopsaltis T, Passias P, Mundis G, Hart R, Neuman B, Klineberg E, Hostin R, Bess S, Deviren V, Ames CP, ISSG (2017) Three-column osteotomy for correction of cervical and cervicothoracic deformities: alignment changes and early complications in a multicenter prospective series of 23 patients. Eur Spine J 26:2128-2138

31. Cloyd JM, Acosta FL, Ames CP (2008) Effect of age on the perioperative and radiographic complications of multilevel cervicothroacic spinal fusions. Spine 33:E977-E982

32. Song KJ, Johnson JS, Choi BR, Wang JC, Lee KB (2010) Anterior fusion alone compared with combined anterior and posterior fusion for the treatment of degenerative cervical kyphosis. J Bone Joint Surg Br 92:1548-1552

33. Mummaneni PV, Dhall SS, Rodts GE, Haid RW (2008) Circumferential fusion for cervical kyphotic deformity. J Neurosurg Spine 9:515-521

34. O'Shaughnessy BA, Liu JC, Hsieh PC, Koski TR, Ganju A, Ondra SL (2008) Surgical treatment of fixed cervical kyphosis with myelopathy. Spine 33:771-778

35. Lee SH, Kim KT, Lee JH, Kang KC, Jang SJ, Hwang SP, Yoon KT (2016) $540^{\circ}$ cervical realignment procedure for extensive cervical OPLL with kyphotic deformity. Spine 41:1876-1883

36. Mehdian SMH, Freeman BJC, Licina P (1999) Cervical osteotomy for ankylosing spondylitis: an innovative variation on an existing technique. Eur Spine J 8:505-509

37. Simmons ED, DiStefano RJ, Zheng Y, Simmons EH (2006) Thirty-Six years experience of cervical extension osteotomy in ankylosing spondylitis. Spine 31:3006-3012

38. Sheshadri V, Moga R, Manninen P, Goldstein CL, Rampersaud YR, Massicotte EM, Fehlings MG, Venkatraghavan L (2017) Airway adverse events following posterior occipito-cervical spinal fusion. J Clin Neurosci 39:124-129

39. Koller H, Koller J, Mayer M, Hitzel W, Hempfing A (2017) Preoperative patient characteristics and pedicle screw placement accuracy impact complication rates with fusion surgery at the cervicothoracic junction. In: Annual meeting of CSRS-Asian Pacific, Kobe/Japan

40. Koller H, Hempfing A, Mayer M, Zenner J, Meier O (2017) Preoperative patient characteristics and pedicle screw placement acuracy impact complications rates with fusion surgery at the cervicothoracic junction. Presented at CSRS-Europe annual meeting, Salzburg, Austria

41. Deviren V, Scheer JK, Ames CP (2011) Technique of cervicothoracic junction pedicle subtraction osteotomy for cervical sagittal imbalance: report of 11 case. J Neurosurg Spine 15:174-181

42. Samudrala S, Vaynman S, Thiayananthan T, Ghostine S, Bergey DL, Anand N, Pashman RS, Johnson JP (2010) Cervicothoracic junction kyphosis: surgical reconstruction with pedicle subtraction osteotomy and Smith-Peterson osteotomy. J Neurosurg Spine 13:695-706

43. O'Neill KR, Lenke LG, Bridwell KH, Neuman BJ, Kim HJ, Archer KR (2015) Factors associated with long-term patientreported outcomes after three-column osteotomies. Spine J $15: 2312-2318$ 
44. Koller H, Meier O, Zenner J, Mayer M, Hitzl W (2013) Noninstrumented correction of cervicothoracic kyphosis in ankylosing spondylitis: a critical analysis on the results of open-wedge osteotomy C7-T1 with gradual Halo-Thoracic-Cast based correction. Eur Spine J 22:747-758

45. Mehdian SMH, Ranganathan A (2011) A safe controlled instrumented reduction technique for cervical osteotomy in ankylosing spondylitis. Spine 36:715-720

46. Samudrala S, Vaynman S, Thiayananthan T, Ghostine S, Bergey DL, Anand N, Pashman RS, Johnson JP (2010) Cervicothoracic junction kyphosis: surgical reconstruction with pedicle subtraction osteotomy and Smith-Peterson osteotomy. J Neurosurg Spine 13:695-706

47. Tokala DP, Lam KS, Freeman BJC, Webb JK (2007) C7 decancellisation closing wedge osteotomy for the correction of fixed cervicothoracic kyphosis. Eur Spine J 16:1471-1478

48. Lee SH, Kim KT, Suk KS, Kim MH, Park DH, Kim KJ (2012) A sterile-freehand reduction technique for corrective osteotomy of fixed cervical kyphosis. Spine 37:2145-2150

49. Guo Q, Ni B, Yang J, Liu K, Sun Z et al (2011) Relation between alignments of upper and subaxial cervical spine: a radiological study. Arch Orthop Trauma Surg 131:857-867

50. Núñez-Pereira S, Hitzl W, Bullmann V, Meier O, Koller H (2015) Sagittal balance of the cervical spine: an analysis of occipitocervical and spinopelvic interdependence, with $\mathrm{C}-7$ slope as a marker of cervical and spinopelvic alignment. J Neurosurg Spine 23:16-23

51. Le Huec JC, Demezon H, Aunoble S (2015) Sagittal parameters of global cervical balance using EOS imaging: normative values from a prospective cohort of asymptomatic volunteers. Eur Spine J 24:63-71

52. Knott PT, Mardjetko SM, Techy F (2010) The use of the T1 sagittal angle in predicting overall sagittal balance of the spine. Spine J 10:994-998

53. Lee S-H, Son E-S, Seo E-M, Suk K-S, Kim K-T et al (2015) Factors determining cervical spine sagittal balance in asymptomatic adults: correlation with spinopelvic balance and thoracic inlet alignment. Spine J 15:705-712

54. Diebo BG, Challier V, Henry JK, Oren JH, Spiegel MA, Vira S, Tanzi EM, Liabaud B, Lafage R, Protopsaltis TS, Errico TJ, Schwab FJ, Lafage V (2016) Predicting cervical alignment required to maintain horizontal gaze based on global spinal alignment. Spine 41:1795-1800

55. Miyamoto H, Hashimoto K, Ikeda T, Akagi M (2017) Effect of correction surgery for cervical kyphosis on compensatory mechanisms in overall spinopelvic sagittal alignment. Eur Spine J 26:2380-2385

56. Lee D-H, Ha J-K, Chung J-H, Hwang CJ, Lee CS, Cho JH (2016) A retrospective study to reveal the effect of surgical correction of cervical kyphosis on thoraco-lumbo-pelvic sagittal alignment. Eur Spine J 25:2286-2293

57. Mizutani J, Abumi K, Endo K, ishii K, Yagi M, Ames C (2017) Cervical reconstruction surgery achieves spinal balance globally. In: Annual meeting of CSRS-Asian Pacific, Kobe/Japan

58. Ramchandran S, Protopsaltis TS, Sciubba D, Scheer JK, Jalai CM, Daniels A, Passias PG, Lafage V, Kim HJ, Mundis G, Klineberg E, Hart RA, Smith JS, Shaffrey C, Ames CP; International Spine Study Group (2018) Prospective multi-centric evaluation of upper cervical and infra-cervical sagittal compensatory alignment in patients with adult cervical deformity. Eur Spine J 27:416-425

59. Mizutani J, Strom RG, Abumi K, Endo K, Ishii K, Yagi M, Verma K, Tay B, Deviren V, Ames CP (2016) Thoracolumbar reciprocal changes after cervical reconsntructive surgery. In: Annual meeting of SRS, Praha/Hungary

60. Tomasino A, Parikh K, Koller H, Zink W, Tsiouris AJ, Steinberger J, Härtl R (2009) The vertebral artery and the cervical pedicle: morphometrical analysis of a critical neighbourhood. J Neurosurg Spine 13:52-60

61. Wollowick AL, Kelly MP, Riew DK (2012) Pedicle subtraction osteotomy in the cervical spine. Spine 37:E342-E348

62. Khoueir P, Hoh DJ, Wang MY (2008) Use of hinged rods for controlled osteoclastic correction of a fixed cervical kyphotic deformity in anklyosing spondylitis. J Neurosurg Spine 8:579-583

63. McMaster MJ (1997) Osteotomy of the cervical spine in ankylosing spondylitis. J Bone Joint Surg 79-B:197-203

64. Fehlings MG, Kato S, Lenke LG, Nakashima H, Nagoshi N, Shaffrey CI, Cheung KMC, Carreon L, Dekutoski MB, Schwab FJ, Boachie-Adjei O, Kebaish KM, Ames CP, Qiu Y, Matsuyama Y, Dahl BT, Mehdian H, Pellisé-Urquiza F, Lewis SJ, Berven SH (2018) Incidence and risk factors of post-operative neurological decline after complex adult spinal deformity surgery: results of the scoli-risk-1 study. Spine J 18(10):1733-1740

65. Smith JS, Ramchandran S, Lafage V, Shaffrey CI, Ailon T et al (2016) Prospective multicenter assessment of early complication rates associated with adult cervical deformity surgery in 78 patients. Neurosurgery 79:378-388

66. Langeloo DD, Journee HL, Pavlov PW, De Kleuver M (2006) Cervical osteotomy in ankylosing spondylitis: evaluation of new developements. Eur Spine J 15:493-500

67. Vialle R, Levassor N, Rillardon L, Templier A, Skalli W, Guigui P (2005) Radiographic analysis of the sagittal alignment and balance of the spine in asymptomatic subjects. J Bone Joint Surg 87(2):260-267

68. Etame AB, Thoi KD, Wang AC, LaMarca F, Park P (2008) Surgical management of symptomatic cervical or cervicothorcic kyphosis due to ankylosing spondylitis. Spine 33:E559-E564

69. Hoh DJ, Khoueir P, Wang MY (2011) Management of cervical deformity in ankylosing spondylitis. Neurosurg Focus 24:9

70. Kurakawa T, Miyamoto H, Kaneyama S, Sumi M, Uno K (2016) C5 nerve palsy after posterior reconstruction surgery: predictive risk factors of the incidence and critical range of correction for kyphosis. Eur Spine J 25:2060-2067

71. Nakashima H, Imagama S, Yukawa $Y$, Kanemura T, Kamiya M, Yanase M, Ito K, Machino M, Yoshida G, Ishikawa Y, Matsuyama Y, Hamajima N, Ishiguro N, Kato F (2012) Multivariate analysis of C-5 palsy incidence after cervical posterior fusion with instrumentation. J Neurosurg Spine 17:103-110

72. Hojo Y, Ito M, Abumi K, Kotani Y, Sudo H, Takahata M (2010) A late neurological complication following anterior posterior correction surgery of severe cervical kyphosis. Eur Spine J $20: 890-898$

73. Blizzard DJ, Gallizzi MA, Sheets C, Klement MR, Kleeman LT, Caputo AM, Eure M, Brown CR (2015) The role of iatrogenic foraminal stenosis from lordotic correction in the development of C5 palsy after posterior laminectomy and fusion. J Orthop Surg Res 6:160

74. Park P, Wang AC, Sangala JR, Kim SM, Hervey-Jumper S, Than KD, Farokhrani A, Lamarca F (2011) Impact of multimodal intraoperative monitoring during correction of symptomatic cervical or cervicothoracic kyphosis. J Neurosurg Spine 14:99-105

75. Qian B-P, Jian J, Qiu Y, Wang B, Yu Y, Zhu Z (2013) Radiographical predictors for postoperative sagittal imbalance in patients with thoracolumbar kyphosis secondary to anklyosing spondylitis after lumbar pedicle subtraction osteotomy. Spine 38:E1669-E1675

76. Lafage V, Schwab F, Vira S, Patel A, Ungar B, Farcy JP (2011) Spino-pelvic parameters after surgery can be predicted: a preliminary formula and validation of standing alignment. Spine 36:1037-1045

77. Lafage V, Bharucha NW, Schwab F, Hart RA, Burton D, BoachieAdjei O, Smith JS, Hostin R, Shaffrey C, Gupta M, Akbarnia 
BA, Bess S (2012) Multicenter validation of a formula predicting postoperative spinopelvic alignment. J Neurosurg Spine 16:15-21

78. Lafage V, Schwab F, Vira S, Patel A, Ungar B, Farcy JP (2011) Spino-pelvic parameters after surgery can be predicted: a preliminary formula and validation of standing alignment. Spine 36(13):1037-1045

79. Gupta MC, Terran JS, Mundis GM, Smith JS, Shaffrey CI (2013) Pedicle subtraction osteotomy (PSO) in the revision versus primary adult spinal deformity (ASD) Patient: Is ere a di erence in correction and complications? In: Annual meeting of SRS, Lyon/ France

80. Blondel B, Schwab F, Bess S, Ames C, Mummaeni PV, Hart R, Smith JS, Shaffrey CI, Burton D, Boachie-Adjei O, Lafage V (2013) Posterior global malalignment after osteotomy for sagittal plane deformity-it happens and here is why. Spine 38:E394-E401

81. Protopsaltis TS, Ramchandran S, Hamilton DK, Sciubba D, Passias PG, Lafage V, Lafage R, Smith JS, Hart RA, Gupta M, Burton D, Bess S, Shaffrey C, Ames CP; International Spine Study Group (ISSG) (2018) Analysis of successful versus failed radiographic outcomes after cervical deformity surgery. Spine (Phila Pa 1976) 43(13):E773-E781

82. Le Huec JC, Cogniet A, Demezon H, Rigal J, Saddiki R, Aunoble S (2015) Insufficient restoration of lumbar lordosis and FBI index following pedicle subtraction osteotomy is an indicator of likely mechanical complication. Eur Spine J 24:S112-S120

83. Schwab F, Patel A, Ungar B, Lafage V (2012) Sagittal realignment failures following pedicle subtraction osteotomy surgery: are we doing enough? Clinical article. J Neurosurg Spine 16:539-546

84. Koller H, Pfanz C, Meier O, Hitzl W, Mayer M, Bullmann V, Schulte TL (2016) Factors influencing radiographic and clinical outcomes in adult scoliosis surgery: a study of 448 European patients. Eur Spine J 25:532-548

85. Yang S, Buchowski JM, Verma V (2015) Construct type and risk factors for pseudoarthrosis at the cervicothoracic junction. Spine 40:E613-E617
86. Hirano K, Matsuyama Y, Sakai Y, Katayama Y, Imagama S, Ito Z, Wakao N, Yoshihara H, Miura Y, Kamiya M, Sato K, Nakamura H, Ishiguro N (2010) Surgical complications and management of occipitothoracic fusion for cervical destructive lesions in RA patients. J Spinal Disord 23:121-126

87. Tanouchi T, Shimizu T, Fueki K, Ino M, Toda N, Manabe N (2014) Adjacent-level failures after occipito-thoracic fusion for rheumatoid cervical disorders. Eur Spine J 23:635-640

88. Shamji MF, Cook C, Pietrobon R, Tackett S, Brown C, Isaacs RE (2008) Impact of surgical approach on complications and resource utilization of cervical spine fusion: a nationwide perspective to the surgical treatment of diffuse cervical spondylosis. Spine J 9:10-16

89. Cole T, Veeravagu A, Zhang M, Azad TD, Desai A, Ratliff JK (2015) Anterior versus posterior approach for multilevel degenerative cervical disease: a retrospective propensity score-matched study of the marketscan database. Spine 40:1033-1038

90. Ramieri A, Domenicucci M, Ciappetta P, Cellocco P, Raco A, Costanzo G (2011) Spine surgery in neurological lesions of the cervicothoracic junction: multicentric experience on 33 consecutive cases. Eur Spine J 20:13-19

91. Yonezawa I, Okuda T, Sakoda J, Nojiri H, Nakahara D, Momomura R (2010) The clinical results of occipito-cervicothoracic fusion in rheumatoid arthritis. In: CSRS-Asia Pacific annual meeting, Kobe/Japan

92. Hart R, Dupaix JP, Rusa R, Kane MS, Volpi JD (2013) Reduction of airway complications with fluid management protocol in patients undergoing cervical decompression and fusion across the cervicothoracic junction. Spine 38:E1135-E1140

93. Pahys JM, Pahys JR, Cho SK, Kang MM, Zebala LP, Hawasli AH, Sweet FA, Lee DH, Riew KD (2013) Methods to decrease postoperative infections following posterior cervical spine surgery. J Bone Joint Surg Am 95:549-554

94. Nottmeier EW, Deen HG, Patel N, Birch B (2009) Cervical kyphotic deformity correction using $360^{\circ}$-degree reconstruction. J Spinal Disord 22:385-391

\section{Affiliations}

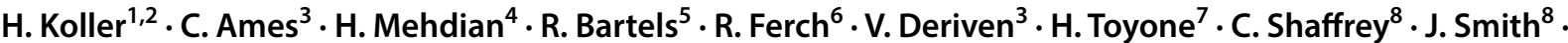 W. Hitzl $\left.\right|^{9}$. J. Schröder ${ }^{10}$. Yohan Robinson ${ }^{11}$}

H. Koller

heiko.koller@t-online.de

1 Spine and Scoliosis Center, Schön Klinik Vogtareuth, Krankenhausstrasse 20, 83569 Vogtareuth, Germany

2 Department for Trauma and Sports Injuries, Paracelsus Medical University, Salzburg, Austria

3 San Francisco, USA

4 Nottingham, UK

$5 \quad$ Nijmegen, Netherlands
6 Canberra, Australia

7 Tokyo, Japan

8 Charlottesville, USA

9 Salzburg, Austria

10 Osnabrück, Germany

11 Stockholm, Sweden 